\title{
Teatro y política en la Atenas clásica desde la mirada de Plutarco
}

Analía Verónica Sapere

Universidad de Buenos Aires / CONICET, Argentina

analiasapere@gmail.com

Recibido: 11/04/2019. Aceptado: 22/10/2019

\begin{abstract}
Resumen
El presente trabajo se propone estudiar la relación entre política y teatro en Atenas clásica en las Vidas paralelas de Plutarco. Intentamos mostrar que, de acuerdo con Plutarco, los políticos atenienses hacen uso de técnicas teatrales para obtener la aprobación del pueblo y así fortalecer su poder. En primer lugar indagaremos en las opiniones literarias de Plutarco acerca del teatro. En segundo lugar nos valdremos de las herramientas del análisis del discurso para abordar las vidas de Alcibíades, Nicias y Pericles, dado que representan tres estilos diferentes de liderazgo. Para finalizar, confrontaremos las conclusiones con la situación en Esparta.
\end{abstract}

PALABRAS CLAVE: Plutarco, Vidas Paralelas, teatro, Atenas, democracia.

\section{Theater and politics in classical Athens according to Plutarch's view}

\begin{abstract}
This paper aims to study the relation between politics and theater in classical Athens in Plutarch's Parallel Lives. We intend to show that, according to Plutarch, Athenian politicians make use of theatrical techniques in order to gain the approval of the people and thus strengthen their power. First we will investigate Plutarch's literary opinions about theater. Secondly, we will use a discourse analysis approach to study the Lives of Alcibiades, Nicias and Pericles, because they represent three different styles of leadership. Finally, we will confrontate the conclusions with the Spartan case.
\end{abstract}




\section{Introducción}

En numerosos pasajes de sus Vidas paralelas Plutarco hace alusión a la forma particular en que las artes se relacionan con la vida política de Grecia antigua. La literatura y más específicamente el teatro suelen ser blanco de ataque por parte del biógrafo, pues su opinión es que tanto cómicos como tragediógrafos, basados sobre todo en rencores y envidias personales, contribuyen a reproducir mentiras y falsedades acerca de los personajes destacados de la política, mentiras que resultan por demás atractivas para el público general pero que obstaculizan la labor historiográfica. A nuestro entender, Plutarco sugiere a su vez que la influencia del teatro excede el escenario de la tragedia y de la comedia, pues los propios políticos y generales son conscientes de la importancia de saber 'actuar' ante el pueblo para lograr sus fines. Existe, pues, una especie de retroalimentación entre lo que ocurre dentro y fuera del teatro, pues no solo los autores de tragedias y comedias despliegan estrategias ficcionales, sino también los propios agentes de la vida política. Pericles, Nicias y Alcibíades son un claro ejemplo de dicha práctica, en tanto que son mostrados por Plutarco como 'actores' y 'autores' (literariamente hablando) de determinadas decisiones de gobierno, generándose así una amplificación de los efectos ficcionales que el discurso teatral ya comporta.

En el marco de lo expuesto, nuestra intención en el presente trabajo es contribuir con la discusión en torno a la relación entre teatro y política en Atenas a partir de la mirada de Plutarco. ${ }^{1}$ Primero analizaremos las opiniones teóricas y filosóficas que esboza nuestro autor acerca de la tensión entre ficción y verdad en el discurso histórico y de qué forma el teatro alimenta dicha tensión. Recurriremos luego a un análisis discursivo para verificar la presencia de vocabulario técnico y metáforas teatrales en la narración plutarquea de asuntos políticos y decisiones de gobierno, lo que a nuestro juicio constituye un procedimiento cohesivo deliberado del biógrafo para destacar la relación de las prácticas teatrales dentro y fuera del escenario. Nos basaremos en el estudio de las Vidas de Alcibíades, Nicias y Pericles, dado que nos servirán para ejemplificar tres tipos distintos de liderazgos. Finalmente, ponderaremos las diferencias que expresa Plutarco entre la práctica teatral ateniense y la espartana, pues a partir de esta comparación se fortalecerán las conclusiones de nuestro trabajo, en tanto que nos permitirá demostrar que, para el biógrafo, la actividad política en el ámbito de la democracia ateniense no está escindida de la actividad teatral, dado que los liderazgos fuertes como los de Nicias, Pericles y Alcibíades requieren para sostenerse del despliegue de montajes artísticos (ficcionales) que den cuenta de las propias hazañas de gobierno, pues estas serán exitosas para el pueblo/público dependiendo de la forma en que sean exhibidas. En términos de Arendt (1961:154):

The performing arts [...] have indeed a strong affinity with politics. Performing artists dancers, play-actors, musicians, and the like need an audience to show their virtuosity, just as acting men need the presence of others before whom they can appear; both need a publicly organized space for their "work," and both depend upon others for the performance itself. Such a space of appearances is not to be taken for granted wherever men live together in a community. The Greek polis once was precisely that "form of government" which provided men with a space of appearances where they could act, with a kind of theater where freedom could appear.

1 Acerca del tema remitimos a la siguiente bibliografía general: De Lacy (1952), Tagliasacchi (1960), Di Gregorio (1976), O’Donnell (1975), Aguilar (1984), Mossman (1988), Braund (1993), Zadorojniy (1997), Papadi (2005 y 2007), Pelling (2002), Muñoz Gallarte (2013) y Pace (2017). 
Aquello que tanto Arendt como otros críticos ${ }^{2}$ han advertido, pero de manera metafórica o como imagen, Plutarco lo exhibirá de manera concreta (esto es, haciendo explícita la teatralidad que llevan a cabo los políticos), en consonancia con su planteo edificador, que busca instruir a los lectores con una caracterización vívida de los personajes retratados y su contexto. Desde luego que Plutarco no tiene como objetivo central de sus Vidas ofrecer un relato fiel de los hechos del pasado, sino tomar a los protagonistas de esos hechos como ejemplos de virtud ${ }^{3}$; por tal motivo, sus opiniones literarias respecto de la comedia ática deben ser interpretadas como una forma de paideía a sus lectores (que reflexiona en torno a temas como la mentira y la verdad, el valor del arte, las virtudes del buen gobernante, etc.) y no como una pretensión de reconstrucción fiel de la vida política ateniense. Esto no invalida, de todas formas, la mirada de Plutarco sobre la temática a analizar, sino que nos advierte respecto de la índole del texto para arribar con solidez a las conclusiones de nuestro trabajo.

\section{Las opiniones metaliterarias de Plutarco}

Es sabido que Plutarco no suele demostrar gran simpatía ni por poetas ni por dramaturgos. Esta postura, de clara influencia platónica, es esbozada, por ejemplo, en el De audiendis poetis, donde dirige consejos a los jóvenes a fin de que aprendan a 'depurar' las obras literarias de lo vano, lo engañoso y lo pernicioso que las caracteriza, y así extraer enseñanzas que lleven en última instancia a la única disciplina que importa cultivar, la filosofía.

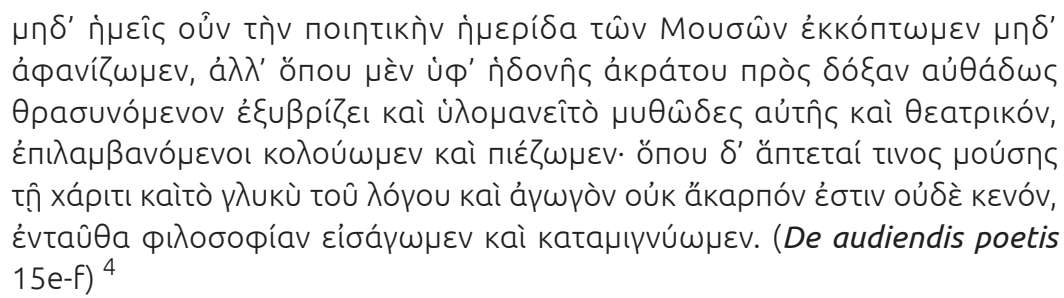

No cortemos nosotros ni suprimamos la vid poética de las Musas, sino que,

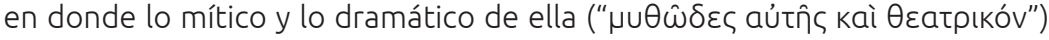
se excede y desborda, animándose con arrogancia por un placer desmedido

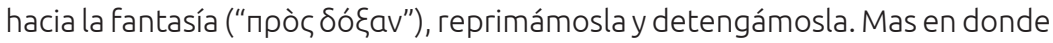
se apodera de cierto arte con gracia, y lo dulce y atrayente de su discurso no es infructífero ni vacío, introduzcamos y mezclemos allí la filosofía.

Plutarco, como Platón, entiende que la poesía no contiene verdad alguna y que las mentiras y exageraciones que encierra (en el pasaje previo aludidas en

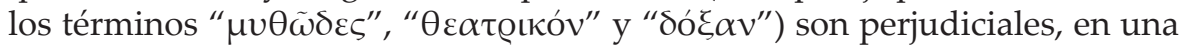
clara inquietud filosófica y moral; pero mientras que uno expulsa a los poetas

2 Somos conscientes de que la relación entre teatro y política no es novedosa (al punto de que es innecesario citar bibliografía que la sustente). No obstante, la forma en que Plutarco la exhibe sí lo es (al menos como planteo por parte de un autor antiguo), según intentaremos probar a partir del abordaje textual que llevaremos a cabo.

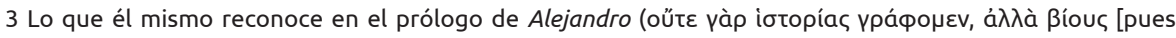

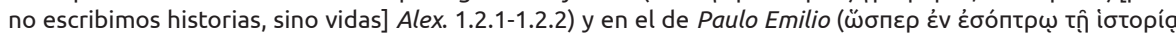

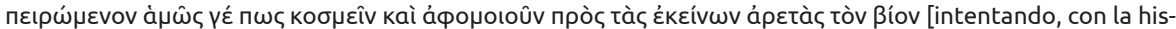
toria, como en un espejo, ordenar mi vida y compararla con las virtudes de aquellos]; Aem. 1.1.2-4) 
de su república ideal, el otro decide instruir al discípulo para encontrar en las obras literarias elementos de utilidad, y de allí que no condene la actividad poética por completo: ${ }^{5}$

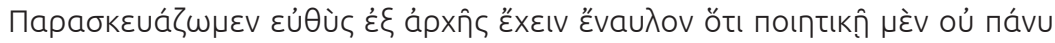

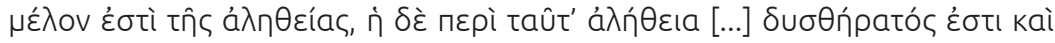

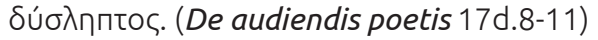

Preparemos al joven directamente desde el principio, para tener siempre resonando en sus oídos que en el arte poético no hay en absoluto algo que se preocupe por la verdad, y que la verdad acerca de esto [...] es algo muy difícil de comprender y difícil de entender.

Si bien Plutarco habla en este tratado de los poetas (aludidos a través de térmi-

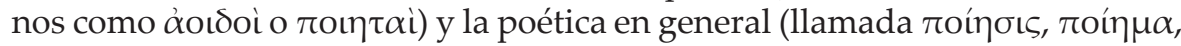

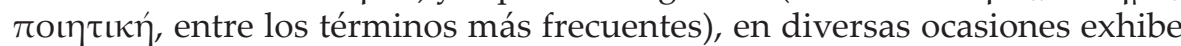
ejemplos de los trágicos atenienses para ilustrar sus opiniones, de modo que debemos entender que su planteo es una crítica amplia a la literatura que incluye también al teatro, lo que resulta de interés para el presente trabajo. ${ }^{6}$

En las Vidas paralelas también hallamos opiniones metaliterarias que apuntan al mismo planteo. La hipótesis central de dichas opiniones es similar a la expresada en los tratados teóricos de Moralia, es decir, una crítica abierta a los poetas y tragediógrafos, aunque aquí la preocupación se basa en la forma en que sus mentiras son un obstáculo para la labor historiográfica. Así, por ejemplo, en Pericles critica a los comediantes (utiliza el apelativo de 'sátiros') y los compara con Estesímbroto cuando se vale del escarnio en su obra histórica:

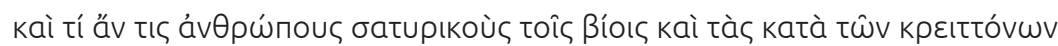

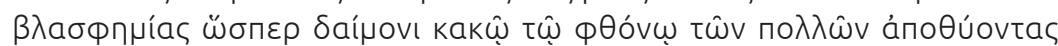

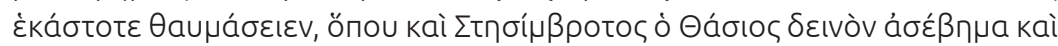

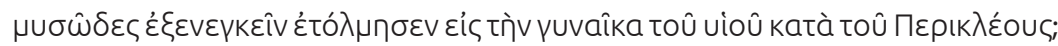

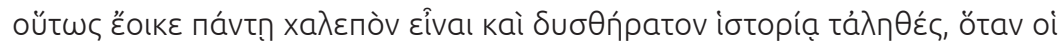

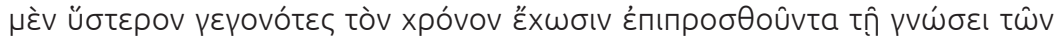

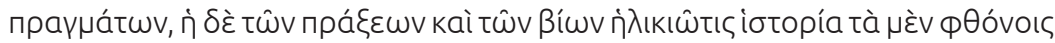

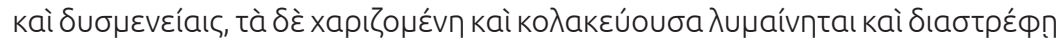

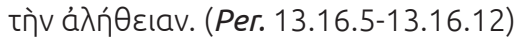

¿Y cómo alguien se podría asombrar de que hombres parecidos a sátiros en sus vidas ofrezcan a la envidia (" $\phi \theta$ óvw") de la multitud blasfemias contra los mejores, ${ }^{7}$ como si estuvieran ofreciendo sacrificios a las malas divinidades, cuando incluso Estesímbroto de Tasos osó expresar contra Pericles una impiedad terrible y abominable respecto de la mujer de su hijo? Así parece que, en general, es penosa y difícil de cazar la verdad en la historia ("ха入єпòv Eivva kaì oӨńpatov"), cuando los que nacieron después tienen al tiempo como un obstáculo ("غ̇пıпробӨoûvta") para el conocimiento de los hechos y cuando

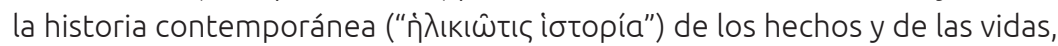

5 Xenophontos (2010:170-171 y 2016:83-84). Sobre la relación de las opiniones esbozadas en este tratado con las ideas platónicas cfr. Bréchet (1999) y Zadorojnyi (2002).

6 Aparecen mencionados reiteradamente Esquilo (17a6, 19f8, 32d6, 36b3, 36b8), Sófocles (16a6, 17c3, 21a10, 21b7, 21f3, 22e16, 23b13, 23e7, 27f5, 33d3) y Eurípides (19e4, 20f5, 22e14, 23b11, 25a10, 25c11, $30 \mathrm{~d} 6,34 \mathrm{~b} 11,36 \mathrm{c} 8)$ así como otros tragediógrafos o alusiones a la tragedia en general $(35 \mathrm{~d} 13,27 \mathrm{f3})$.

7 Aquí se está refiriendo a las burlas de los comediantes contra Fidias, acusado de recibir secretamente mujeres en sus obras para pactar encuentros sexuales con Pericles, entre otras cosas. 
a veces por envidia y enemistad y otras veces por indulgencia y adulación,

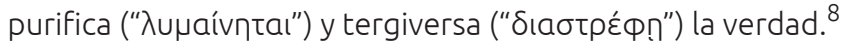

La obra de Estesímbroto, logógrafo del siglo $\mathrm{V}$ a.C., se conserva fragmentariamente (cfr. FGrH $107 \mathrm{~F}$ 10b). Se sabe que escribió una especie de panfleto en contra de Temístocles, Pericles y Tucídides, que es empleado como fuente de algunas Vidas atenienses de Plutarco, probablemente por el carácter biográfico del escrito. ${ }^{9}$ Dado que es contemporáneo de los personajes a los que ataca, se advierte su involucramiento personal en los temas y, por ende, su parcialidad, lo que lo lleva a plasmar en su texto exageraciones y difamaciones, como señala aquí Plutarco. ${ }^{10}$ Conviene no perder de vista que Estesímbroto era además (y principalmente) un rapsodo, y tenía buena reputación como recitador de los poemas épicos (cfr. Platón, Ion, 530cd; Jenofonte, Smp. 3.6, y Engels, 1998:51; Vanotti, 2010), por lo que no es imposible pensar que, desde la mirada de Plutarco, la sensibilidad poética de Estesímbroto puede estar influyendo en su actividad de logógrafo, con las consecuencias negativas que se desprenden de ello (fundamentalmente, la mentira).

En la misma biografía también censurará al poeta trágico Ión de Quíos (FGrH 392 F), por describir a Pericles como vanidoso y jactancioso: “ó $\delta \dot{\varepsilon} \pi 0 \imath \eta \tau \eta ̀ \varsigma$ ”I $\mathrm{T} \omega$

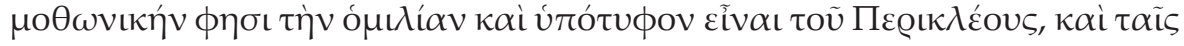

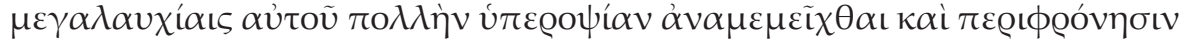
$\tau \tilde{\omega} v \not \alpha \lambda \lambda \omega v^{\prime \prime}$ [El poeta Ión dice que el trato de Pericles era presuntuoso y arrogante, y que su gran desprecio y desdén hacia los demás estaban mezclados con jactancias] (Per. 5.3.1-4). Plutarco entiende que esta apreciación es completamente injusta, por exagerada y maliciosa, pues está en consonancia con el estilo de Ión, quien refiere los hechos históricos como si fueran un drama satírico en el marco de una representación teatral, y, por lo tanto, los tergiver-

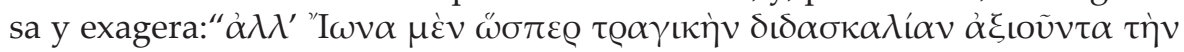

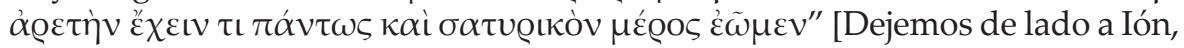
quien, como si fuera una representación teatral, considera que la virtud tiene siempre una parte de drama satírico.] (Per. 5.3.6-8). ${ }^{11}$ Plutarco señala además que Ión tiene, por contraste, una opinión sumamente elogiosa de Cimón, rival político de Pericles (quien muestra elegancia, suavidad y buenos modales:

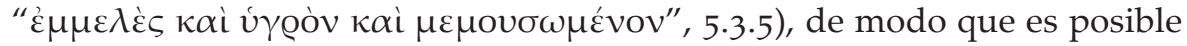
interpretar que la exageración que imprime en esa descripción 'teatral' está basada en la antipatía hacia el personaje. ${ }^{12}$

8 Acerca de la desconfianza de Plutarco respecto de sus fuentes cfr. Pauw (1980), Shipley (1997:3, 53-54, 77, 213), Duff (1999:186) y Cook (2001, con bibliografía).

9 Cfr. Cim. 4.4-8, 4.5, 14.3-5, 16.1-3 y Them. 2.5-6, 4.4-5, 24.6-25.1.

10 Por tal motivo, Von Wilamowitz-Möllendorff (1877:362) lo califica de 'periodista' (Journalist). Cfr. además Schachermeyr (1965), Meister (1978), Strasburger (1986), Tsakmakis (1995), Vanotti (2013). Para un estado de la cuestión acerca de la reconstrucción de la figura de Estesímbroto cfr. Engels (1998) y Vanotti (2011)

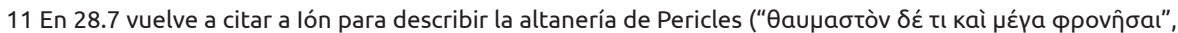
28.7.5), pero aquí usa estas palabras en favor del general, tergiversando probablemente la intención de lón (Pelling, 2007:103-105). Sobre las apariciones de lón en la obra de Plutarco cfr. Huxley (1965: 29) y Pelling (2007). Sobre la obra en general de lón cfr. Jacoby (1947).

12 En Per. 28.2-3 hace una reflexión similar, esto es, califica de 'teatral' el relato del Duris de Samos por

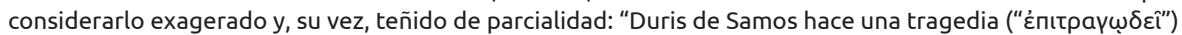
de esto, acusando a los Atenienses y a Pericles por su mucha crueldad, que no relatan ni Tucídides ni Éforo ni Aristóteles. [...] En efecto, Duris, que ni siquiera cuando no tiene un sentimiento particular acostumbra asimilar su narración a la verdad, parece exagerar más las desgracias de su patria, como calumnia ( $\delta ı$ ıßoṇ̂) a

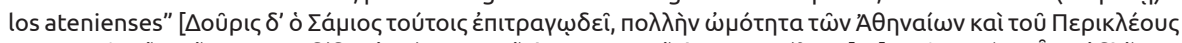

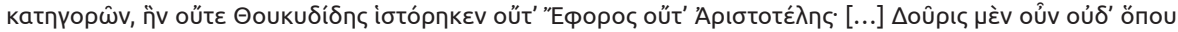

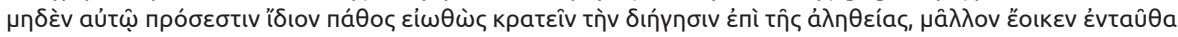

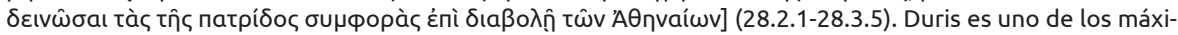
mos representantes de la corriente llamada 'Historiografía trágica', de la que Plutarco se aparta, por los 
En vinculación con esto, Plutarco también esboza una crítica concreta hacia el teatro ateniense. Dice en la Vida de Teseo:

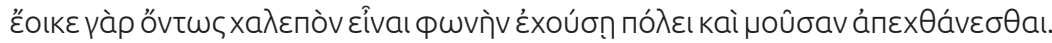

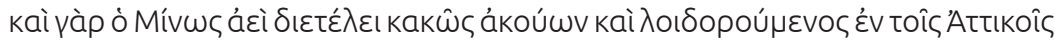

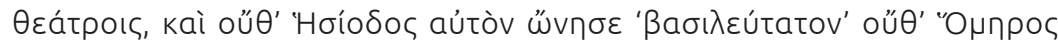

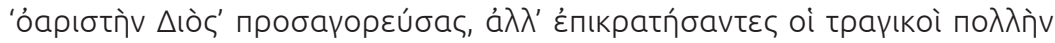

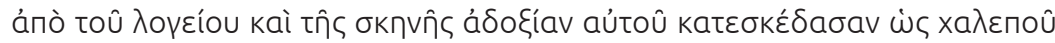

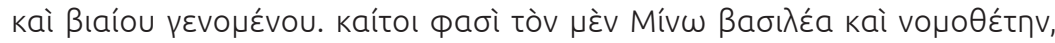

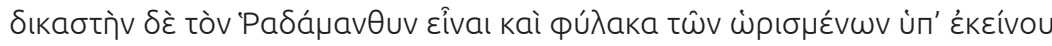
Sikaíwv. (Thes. 16.3.2-16.4).

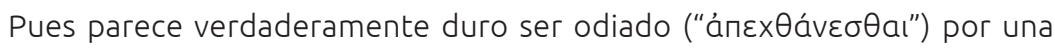
ciudad que tiene voz y arte. Pues incluso Minos siempre era criticado y denostado en los teatros áticos ${ }^{13}$ y ni Hesíodo lo ayudó [al llamarlo] 'el más regio' ni Homero, al referirse a él como 'el más amigo de Zeus', ${ }^{14}$ sino que, los trágicos, al prevalecer, diseminaron su muy mala reputación ("ảookíav") desde el escenario y desde el teatro, como si hubiera sido duro y violento. Afirman, empero, que Minos era rey y legislador y Radamante era juez y guardián de las determinaciones legales de aquél. Dicen, por el contrario, que Minos fue rey y legislador, y Radamante, su juez y guardián de las normas fijadas por aquél. ${ }^{15}$

El autor se muestra disgustado por la manipulación que puede significar el discurso teatral en el seno de la sociedad ateniense y con un tono irónico refiere en este pasaje el odio que experimentaron los ciudadanos hacia Minos, al punto de que los hizo tergiversar o al menos exagerar sus rasgos de crueldad, cuando son conocidas otras versiones que hablan de él como un rey justo.

Ahora bien, la dinámica de este discurso teatral es más compleja que la mera influencia sobre el público general. Plutarco entiende que esa teatralidad forma parte intrínseca de la manera de hacer política y los hombres más poderosos de Atenas han comprendido dicha dinámica y han sabido encauzarla a su favor. Hay múltiples anécdotas en las Vidas que dan cuenta de esta afición teatral de parte de políticos y generales (en tanto actividad mimética ${ }^{16}$ ) y del grado de consciencia que manifiestan al respecto, tal como analizaremos a continuación. Veremos, entonces, que para Plutarco el teatro es un fenómeno vivo, imbricado profundamente en la vida ciudadana, pues sólo desde esta concepción es que se entiende el afán de los políticos por reproducir los esquemas que allí se presentan. ${ }^{17}$

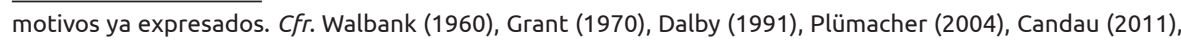
Reichardt (2008), Naas, Simon (2016), Baron (2017).

13 Minos es tema de tragedias hoy perdidas: Cretenses de Esquilo, Dédalo de Sófocles y Cretenses o Teseo de Eurípides.

14 Hes. Fr. 103 Rzach; Hom., Od. XI, 568.

15 Cfr. Ps.-Pl., Min. 320b-c.

16 Entendiendo que la labor del actor es eminentemente mimética. Cfr. Van der Stockt (1990), Muñoz Gallarte (2013) y Pace (2017:134).

17 Como señala Gallego (2003:411): “El teatro [...] es un espectáculo ligado a la pólis democrática que convoca la mirada de un público de ciudadanos, al que implica en una participación colectiva en función de pensar sobre la propia condición de la ciudad". 


\section{La teatralidad de los actos de gobierno: los casos de Alcibíades, Nicias y Pericles.}

Alcibíades es retratado por Plutarco como un maestro a la hora de manejar su imagen pública en diversos campos (Duff, 2005:165; Gribble,1999:267, etc.). Sus donaciones a la ciudad y coregías eran, según la biografía, exce-

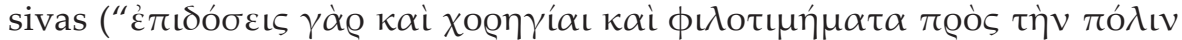
v́ $\pi \varepsilon \varrho \beta 0 \lambda \eta \eta v^{\prime \prime}, 16.4$ ), pero de esta forma (sumado a su elocuencia, belleza y linaje) conseguía ser perdonado por sus errores ("Tá $v \tau \alpha \tau \tilde{\alpha} \lambda \lambda \alpha \sigma v \gamma \chi \omega \varrho \varepsilon \tilde{\imath} \nu$ غ̇ंoó $\left.\varepsilon \iota^{\prime \prime}\right)$. En Alcibíades 9, por ejemplo, se narra la particular historia de cómo éste le corta la cola a su perro y se muestra complacido cuando se entera de que los atenienses lo critican por ello, dado que lo había hecho de manera deliberada, pues de esta forma no lo criticaban por cosas peores: "' $\gamma \dot{i} v \varepsilon \tau \alpha$ เ

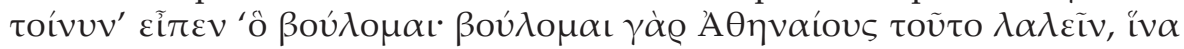

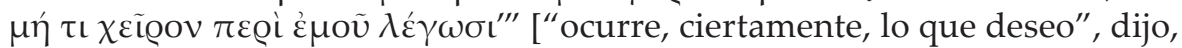
"pues quiero que los atenienses hablen de esto, para que no digan algo peor sobre mí"] (Alc. 9.2.3-9.2.5). También se menciona cómo envidiaba a Nicias por su buena reputación luego de haber obtenido la paz, ${ }^{18}$ moti-

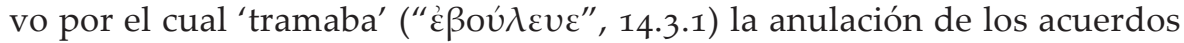
con los lacedemonios, irritaba continuamente a los atenienses en contra de

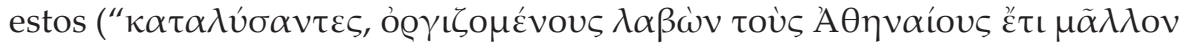

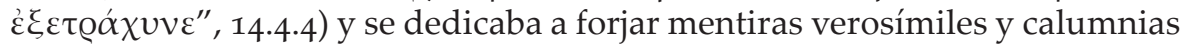

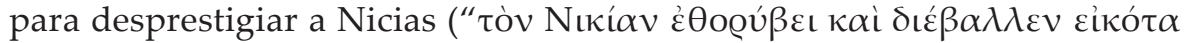
$\left.\kappa \alpha \tau \eta \gamma о \varrho \tilde{\omega} v^{\prime \prime}, 14.4 \cdot 5\right)$. La anécdota más relevante al respecto es la actuación que lleva a cabo Alcibíades con los embajadores lacedemonios: cuando se entera de que se presentarán en la asamblea consigue una entrevista previa con ellos para empezar a desplegar su plan y así sabotear a Nicias. Sugestivamente, para señalar de qué modo Alcibíades logra la entrevista,

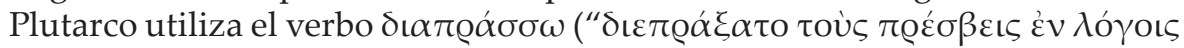

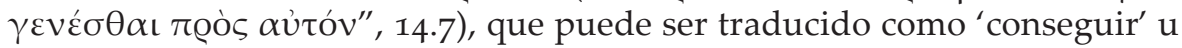
'obtener' pero, en voz media, como es empleado aquí, puede tener el sentido de 'armar una intriga' ${ }^{19}$ En la entrevista (que es ni más ni menos que una trampa) Alcibíades convence a los lacedemonios de que no deben presentarse en la asamblea diciendo que llegan con plenos poderes, aduciendo que esto será tomado de mala manera por los atenienses. Por tal motivo, les asegura que él mismo garantizará el éxito del encuentro, mientras no anuncien sus poderes. Desde el punto de vista estilístico, resulta interesante que Plutarco expone aquí las palabras de Alcibíades en discurso directo (recurso no muy frecuente en las Vidas), reforzando el valor teatral de lo narrado. ${ }^{20}$

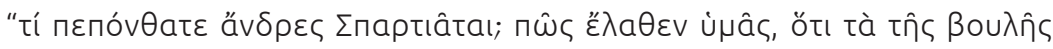

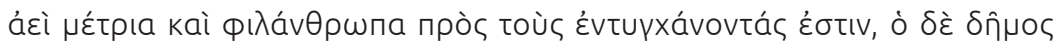

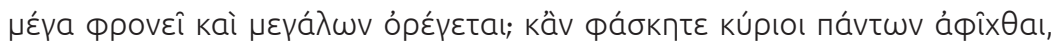

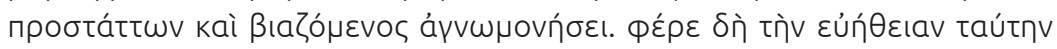

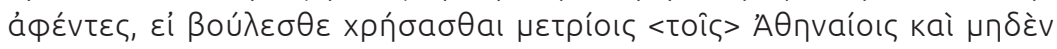

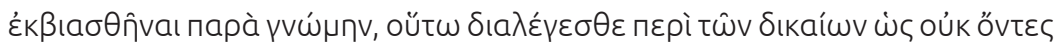

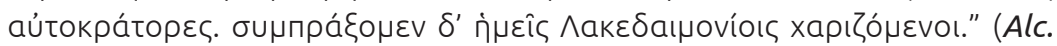
14.8-14.9)

18 Cfr. Th. VI.89.2 y Plu., Nic. 7-9.

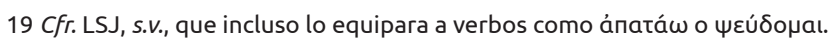

20 Acerca del uso del discurso directo como un procedimiento discursivo poco frecuente en las Vidas y, por ende, digno de atención, cfr. Pelling (1988:316) y Verdegem (2010:86). 
"¿Qué os sucede, espartiatas? ¿Cómo no os disteis cuenta de que las decisiones de la bulé son siempre mesuradas y amistosas hacia los que se presentan ante ella, mas el pueblo es altenero y aspira a grandes cosas? Si decís que venís teniendo plenos poderes, os tratará injustamente, dando órdenes y forzándoos. ¡Vamos! Abandonad esa simpleza, si queréis tratar con atenienses mesurados y no ser forzados a nada contra vuestra opinión; discutid así acerca de lo justo, como si no fuerais plenipotenciarios. Yo los ayudaré, para agradar a los lacedeomonios".

El histrionismo de Alcibíades se refleja en los recursos expresivos que utiliza: el tono coloquial de la frase inicial " $\tau$ í $\pi \varepsilon \pi o ́ v \theta \alpha \tau \varepsilon$ ", de gran fuerza dramática, ${ }^{21}$ la acumulación de preguntas (" $\tau$ í ... $\pi \tilde{\omega} \varsigma . .$. "), el uso de la interjección (" $\phi \varepsilon ́ \varrho \varepsilon ")$ y recomendaciones suaves que encubren en realidad amenazas

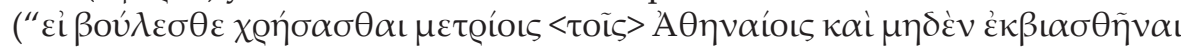
$\left.\pi \alpha \varrho \alpha \gamma \gamma \nu \omega \mu \eta v^{\prime \prime}\right){ }^{22}$ Finalmente, cuando se reúnen en asamblea y Alcibíades les

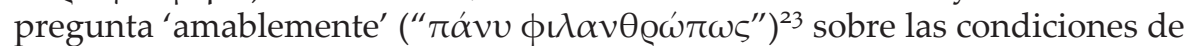
su llegada, los lacedemonios niegan tener plenos poderes (según lo pactado),

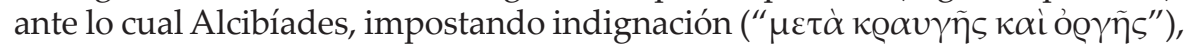
los trata de poco fiables y tramposos, argumentando que poco antes habían afirmado lo contrario. Debido a esta estratagema fracasa el acuerdo. ${ }^{24}$ Plutarco comenta que su actitud había resultado convincente en un primer momento a los embajadores, y por eso confiaron en él. ${ }^{25}$ Señala, por último, que Nicias se enfureció completamente ante el hecho, pero que en ningún momento reco-

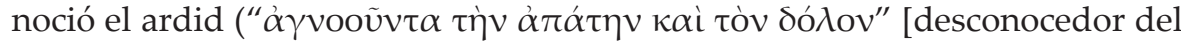
engaño y la mentira], 14.12), lo que da cuenta de las habilidades actorales de su rival.

Agreguemos un elemento más a esta caracterización: Plutarco da a entender que la apelación a lo teatral es un instrumento político para Alcibíades pero también un elemento intrínseco a su personalidad. En efecto, el general simplemente capitaliza la faceta histriónica que le viene dada por naturaleza. Así, por ejemplo, en la anécdota que refiere su entrada a la vida pública, Plutarco pone en evidencia un despliegue escénico (grotesco, ridículo, cómico) que signará su carrera política de allí en más:

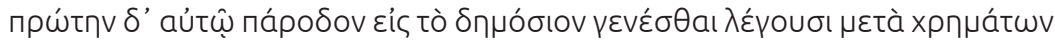

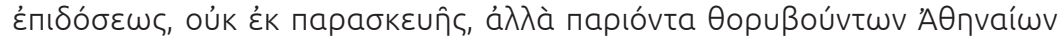

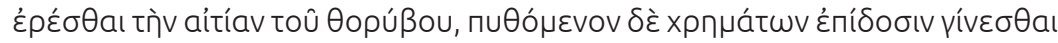

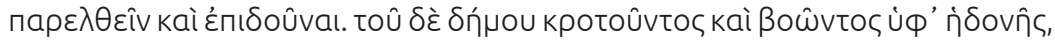

21 LSJ (s.v. náoxw) registra usos del pronombre interrogativo tí con el verbo náoxw en segunda pesona

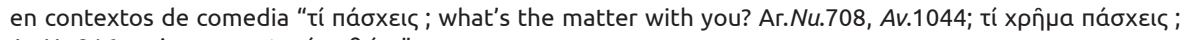
Ar.Nu.816: so in aor. part., tí naقúv;"

22 El texto de Tucídides (V.45), que es la fuente que sigue Plutarco, ofrece simplemente un relato en tercera persona del hecho. Este estilo le permite explicitar las intenciones de Alcibíades, lo que Plutarco no hace, porque evidentemente está privilegiando la teatralidad de la escena y, por ende su exterioridad.

23 Lo que es una clara ironía. Con esta expresión Plutarco nos advierte una vez más sobre la puesta en escena que monta Alcibíades y sobre su habilidad para mentir.

24 Pasaje también referido en Th. V.45 y Plu. Nic. 10.4.

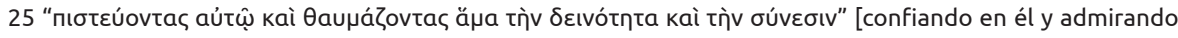
su habilidad e inteligencia, 14.10]. Esto se vincula con algo que también es recurrente en la biografía, la habilidad oratoria de Alcibíades, gracias a la cual consigue enmascarar sus verdaderas intenciones. Plutarco

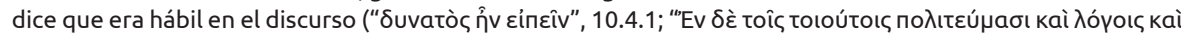

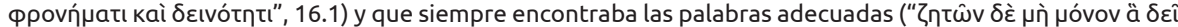

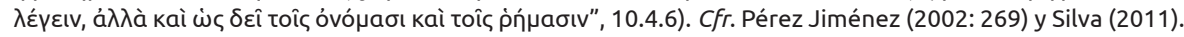
No es lugar aquí para ahondar en las relaciones entre retórica y teatro. Remitimos para ello a Ober (1991), Bers (1994), Harding (1994), Rosenbloom (2009), Sansone (2012), Crick (2015), entre otros. 


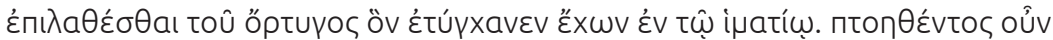

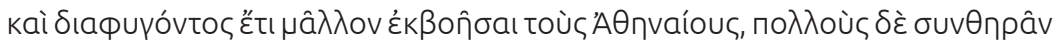

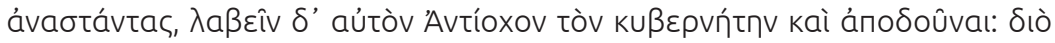

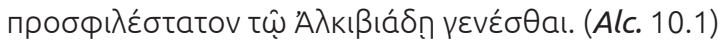

Su primera entrada en la vida pública dicen que fue en una donación de dinero, sin preparación, sino que, al pasar por allí, exaltados los atenienses, preguntó cuál era la causa de la exaltación, y tras averiguar que se trataba de una donación de dinero, se presentó e hizo una donación. Aplaudiendo y gritando el pueblo por la alegría, se olvidó del pájaro que tenía en el manto. Tras asustarse el pájaro y echarse a volar, los atenienses gritaban aún más y muchos se levantaban para atraparlo; lo toma Antíoco, el piloto, y lo devuelve: por eso se volvió el más querido para Alcibíades.

Nótese que el hecho es definido como una $\pi$ ápoðos, un término técnico de la práctica teatral. ${ }^{26}$ Se trata, por otra parte, de una improvisación ("oủ k̇k $\left.\pi \alpha \varrho \alpha \sigma \kappa \varepsilon v \tilde{\eta} \varsigma^{\prime \prime}\right)$, con lo que queda demostrada la naturalidad del personaje a la hora de teatralizar los actos que protagoniza. Por último, el pueblo es descripto como un espectador que aplaude y grita ante la presencia de Alcibíades

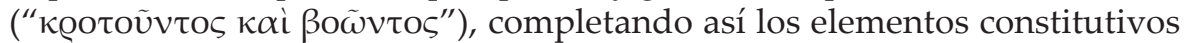
del drama. Salcedo Parrondo (2005), siguiendo una interpretación de Mueller

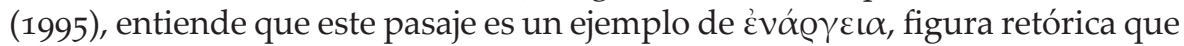
consiste en imprimir vivacidad a lo narrado, a fin de persuadir a los lectores de una manera más firme, en tanto que se los insta a desarrollar imágenes mentales que los transforman prácticamente en testigos oculares. ${ }^{27}$ A nuestro

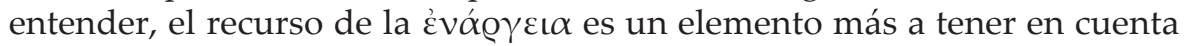
como parte del dispositivo desplegado por Plutarco para enfatizar el carácter dramático de la vida de su retratado: al ofrecer a los lectores una semblanza tan vivaz y patente, los pone a ellos mismos como espectadores de un hecho que los propios atenienses ya presenciaron como teatral.

Y así como el inicio de la carrera política de Alcibíades es teatral, su finalización también, de modo que podemos poner ambas narraciones en paralelo. Plutarco describe su vuelta a Atenas como un espectáculo pero, a diferencia del episodio de la codorniz, donde, decíamos, se observa la naturalidad (la improvisación) con la que fue ejecutado, en este regreso se enfatiza la intencionalidad del general por montar una puesta. Dispone primero la escenogra-

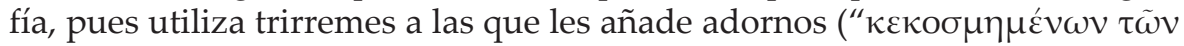

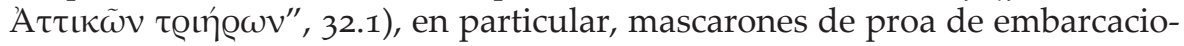
nes que no habían sido capturadas por él, porque deseaba 'ser contemplado'

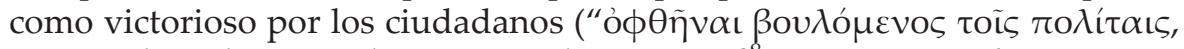

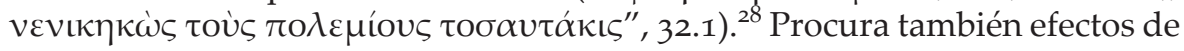
sonido, puesto que, según una de las fuentes que sigue Plutarco, traía un flau-

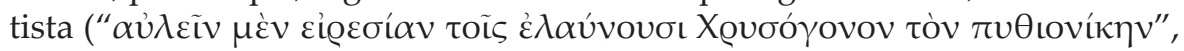
32.3). ${ }^{29}$ La parte teatral está garantizada además por la presencia de un actor

26 El término aparece también enfatizando un efecto teatral en Pompeyo 22.5 y en Praecepta gerendae reipublicae $805 d 3$, según analiza Papadi (2007:133-134).

27 Sobre la importancia persuasiva de la enárgeia cfr. Plett (2012), Webb (2016:87-106) y O'Connell (2017), quienes trabajan además con las fuentes clásicas sobre el tema. Acerca de la relación entre enárgeia y relato histórico, cfr. Walker (1993), Zangara (2008), Soares (2011).

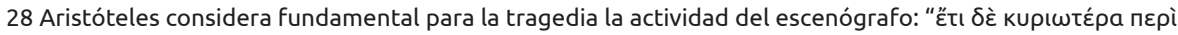

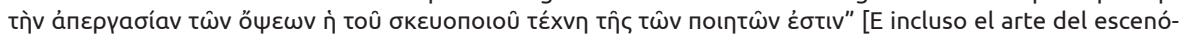
grafo es más importante, para la realización del espectáculo, que el (arte) de los poetas] (Po. 1450b.19-20).

29 La música es para Aristóteles uno de los elementos constitutivos de la tragedia, y uno de los 
de tragedias, Calípides, que se desempeñaba como director de los remeros

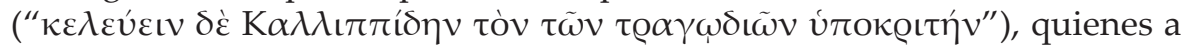
su vez estaban disfrazados con mantos y finas túnicas, como los vencedores

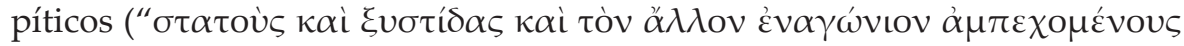

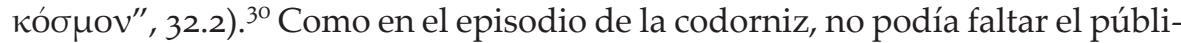

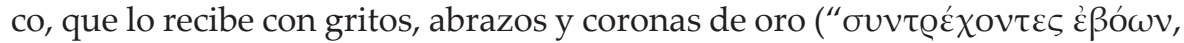

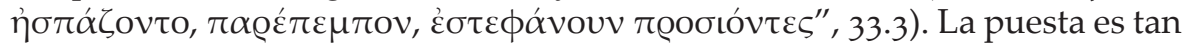
grande, que incluso es vista desde lejos por quienes no habían podido llegar

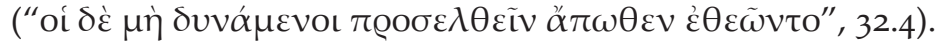

Pero tal vez el pasaje más significativo acerca de la plasticidad actoral de Alcibíades lo hallemos en el capítulo 23: cuando el general ateniense huye a Esparta luego de la expedición de Sicilia, éste adopta las costumbres y forma de ser de los espartanos; asimismo, cuando debe huir de Esparta hacia Oriente, también se adecua a sus formas:

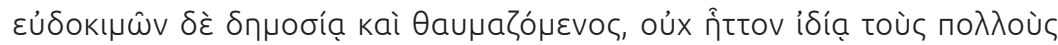

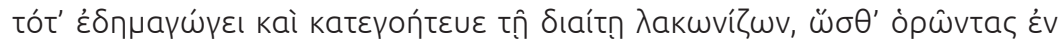

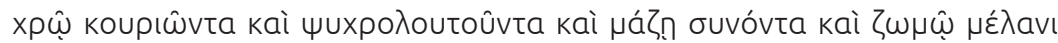

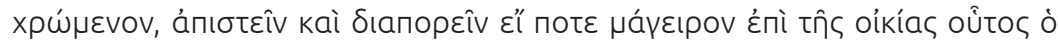

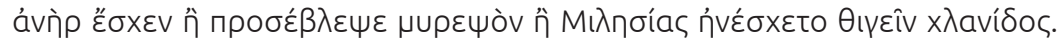

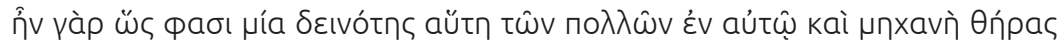

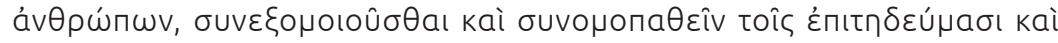

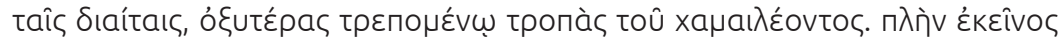

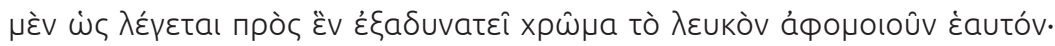

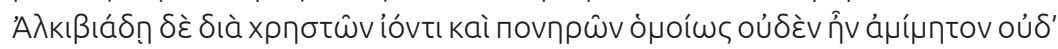

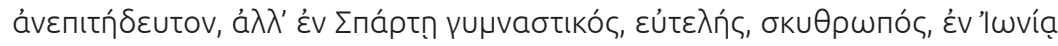

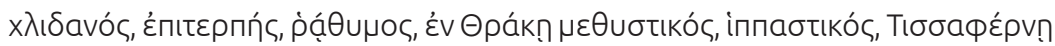

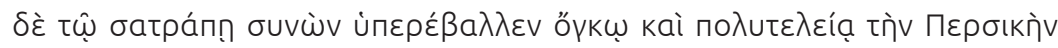

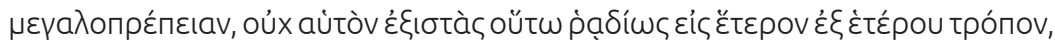

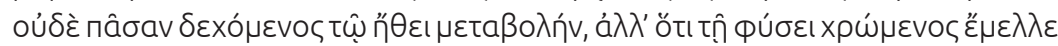

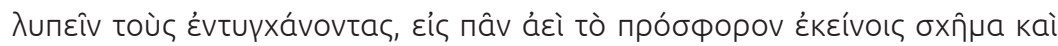

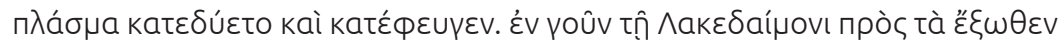

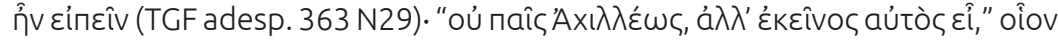

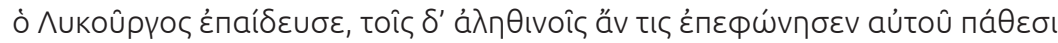

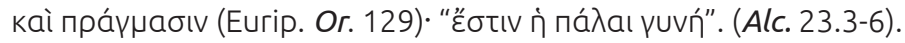

Siendo influyente y admirado en público, en privado se ganó — no en menor

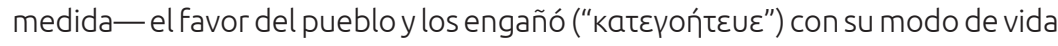
lacónico, de suerte que, viéndolo ("òpûvtac") rapado al ras y lavarse con agua fría y acostumbrado a comer el pan y el caldo negro [i.e., de los espartanos], no lo creían y se preguntaban si alguna vez tuvo este hombre en su casa un cocinero, si vio un perfume o si pudo tocar una clámide milesia. Pues esta

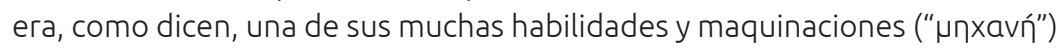

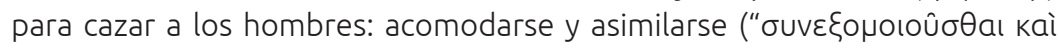

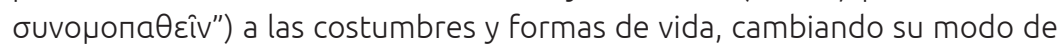

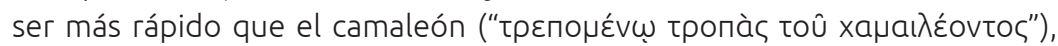
excepto que aquel, según dicen, no puede mudarse al color blanco. Pero para Alcibíades, que pasaba por lo bueno igual que por lo malo, no había nada imposible de imitar ("áuíf nтtov") ni imposible de emprender, sino que

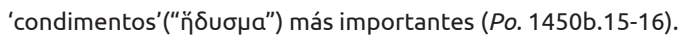

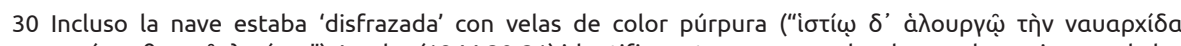

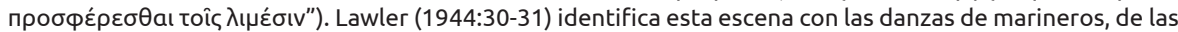
que recaba varios testimonios antiguos. 
en Esparta se ejercitaba y era ahorrativo y taciturno; en Jonia era lujurioso, entregado a los placeres y despreocupado; en Tracia, borracho y aficionado a las carreras de caballos; estando con el sátrapa Tisafernes, sobrepasaba la extravagancia y magnificencia persa, y no cambiando tan fácilmente su forma de ser a otra, ni admitiendo toda mutación en su carácter, sino que, como no quería importunar a aquellos con los que se encontraba, con su naturaleza se

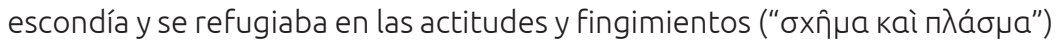
que fueran adecuadas para ellos. En efecto, en Lacedemonia, acerca de su aspecto era posible decir "No eres el hijo de Aquiles, sino aquél en persona" (TCF adesp. 363 N29), como Licurgo lo educó, pero por sus pasiones y actos, alguno habría exclamado "Es la misma mujer de antes" (Eurip. Or. 129). ${ }^{31}$

Plutarco refuerza el contenido del pasaje, que describe a la perfección la destreza mimética de Alcibíades, con una concentración de términos asociados a lo teatral: el uso de la $\mu \eta \chi \alpha \nu \eta$, la mención de la exterioridad (" $\left.\varepsilon \xi \xi \omega \theta \varepsilon v^{\prime \prime}\right)$, el hecho de que los extranjeros 'lo ven' como a uno de ellos ("ó@ $\tilde{\omega} \nu \tau \alpha \varsigma^{\prime \prime}$ ), la posibilidad de Alcibíades de acomodarse y asimilarse a las formas de vida

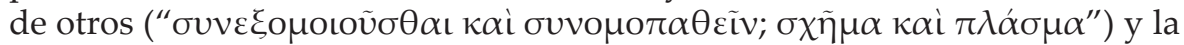

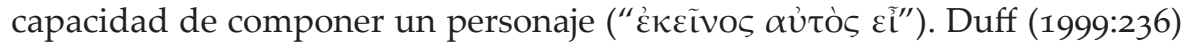
llama la atención acerca del uso de citas textuales (la primera, de una tragedia de autor desconcido; la segunda, del Orestes de Eurípides), que también otorgan teatralidad al pasaje. ${ }^{32}$

En este punto es pertinente establecer la comparación con la descripción que ofrece Plutarco de Nicias, para la que toma como fuente principal a Tucídides, aunque añadiendo aspectos subjetivos que no están en el texto del historiador. ${ }^{33}$ Nicias, a diferencia de Alcibíades, juega el papel de tímido ante el público. Es proverbial su cobardía y temerosidad (como han señalado, entre otros, Westlake, 1941; Gil Fernández, 1962; Lateiner, 1985; Atkinson, 1995, y Titchener, 2008), pero Plutarco destaca que Nicias aprovecha esta situación y afianza dicha imagen ante la masa, 'apareciendo' así como popular. Primero, en 2.6, Plutarco explica que la imagen de temeroso beneficia a Nicias ante el pueblo:

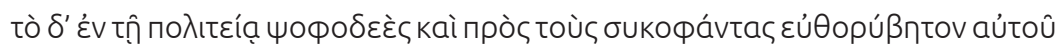

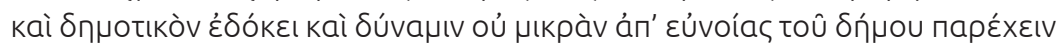

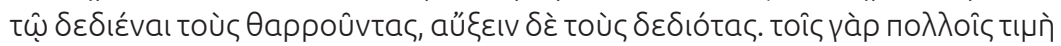

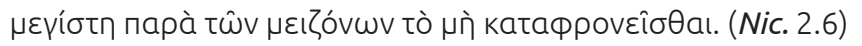

En la política, su timidez y turbación ante los sicofantas lo hacían parecer

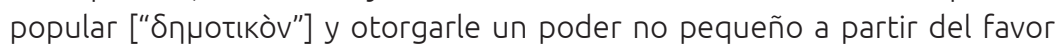
del pueblo, porque teme a los osados y se exalta con los que temen. Pues la mayor honra para la multitud es no ser despreciada por los más grandes.

Luego, el biógrafo explicará en qué consiste la estrategia de Nicias para sacar provecho de dicha imagen, apelando a una cuidada selección léxica:

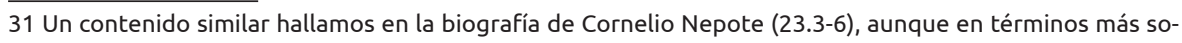
brios y sin destacar el elemento teatral.

32 El autor interpreta aquí (y a la luz de otros pasajes) un juego con la imagen femenina de Alcibíades, que no desarrollamos para no desviarnos de nuestro tema central, pero que sí es interesante tener en cuenta en vinculación con la versatilidad actoral que aquí analizamos. Sobre la relación entre Alcibíades y Aquiles, cfr. Bloedow (1990), Hobbs (2006:254-260), Michelakis (2007:11-12), Verdegem (2010:276-278).

33 Sobre las fuentes de la biografía cfr. Holden (1887:xlii-lx), Perrin (1902), Westlake (1941:63-64) y Gil Fernández (1962). 


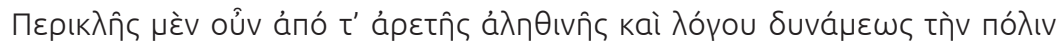

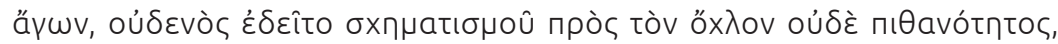

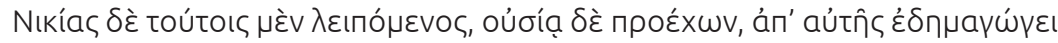

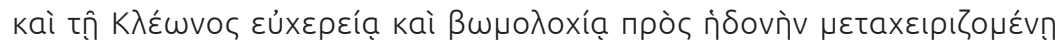

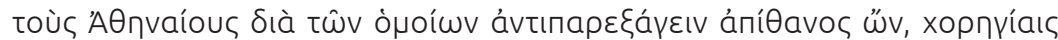

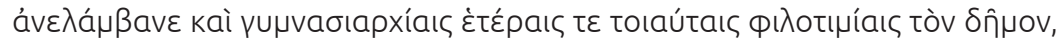

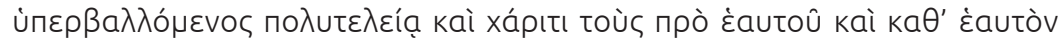
ănavtaç. (Nic. 3.1-2).

En efecto, Pericles no necesitaba de ningún tipo de estratagema

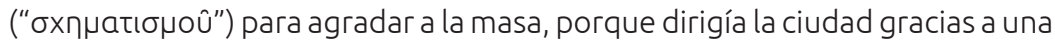

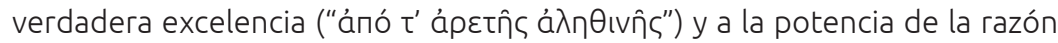

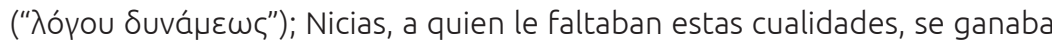
("пров́xwv") $)^{34}$ el favor del pueblo con su riqueza; y como no se sentía seguro para equipararse por métodos similares a la habilidad y bufonería de Cleón, con

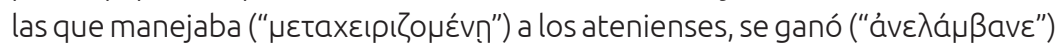
al pueblo con gastos de coregía y gimnasiarquía y otros honores similares, sobrepasando con extravagancias y favores a todos los anteriores a él y a sus contemporáneos.

Nicias, consciente de su falta de atributos naturales, decide que tendrá que exhibir (" $\pi \varrho \circ \varepsilon ́ \chi \omega \nu$ ") una imagen distinta a la de otros políticos para ganarse

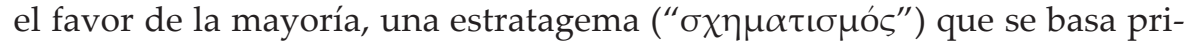
mero en el uso de dinero y regalos. No obstante, la imagen también será construida a partir de esos mismos atributos a priori negativos que ya se han mencionado, pero que aparecerán luego desarrollados en la biografía. Plutarco menciona que Nicias se muestra temeroso de los sicofantas (" $\pi$ @ò

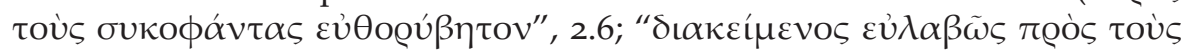

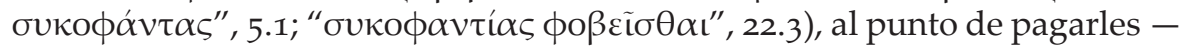
según una cita de Teleclides - para mantenerlos alejados (" $\tau \varepsilon ́ \sigma \sigma \alpha \varrho \alpha \varsigma \delta \dot{\varepsilon} \mu \nu \tilde{\alpha} \varsigma$

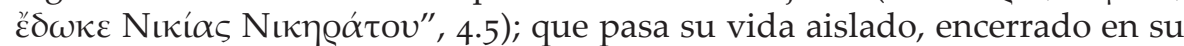

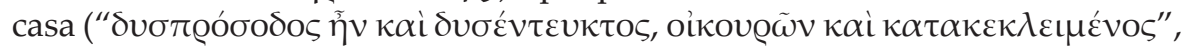

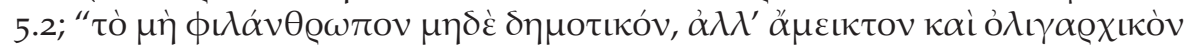

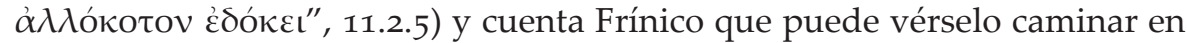

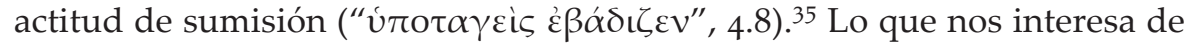
esta descripción es que Plutarco afirma que hay una clara intencionalidad por parte del general ateniense de transmitir dicha imagen de temeroso, solitario e inseguro. Es decir, más allá de si se trata o no de atributos naturales, lo que Plutarco pone en evidencia es que Nicias capitaliza políticamente su carácter tímido y temeroso y crea a partir de ello un personaje que le sirve para ser bien recibido por el pueblo. Pero la estrategia es aún más compleja: Plutarco menciona que quien asiste a Nicias en esta tarea es un tal Hierón, personaje

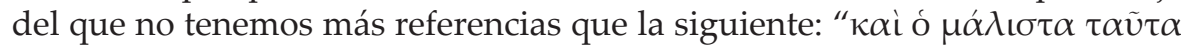

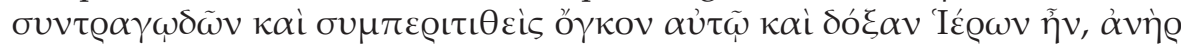

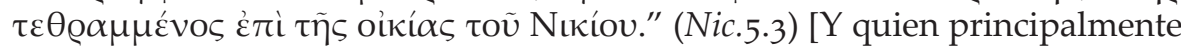

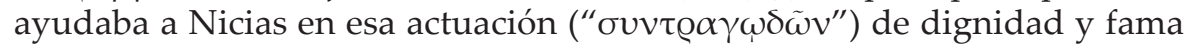
y contribuía con ella era Hierón, un hombre que había crecido en la casa

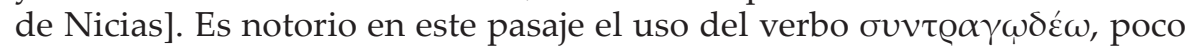
frecuente en la lengua griega, que puede significar tanto 'participar en una

34 Пров́xw (de acuerdo con LSJ, s.v.) puede querer decir 'ganar, retener, mantener' ("hold, hold febore oneself") pero también tiene un sentido metafórico de 'poner como pretexto', 'simular' ("put forward as a pretext, pretend").

35 Es evidente el tono de burla hacia el personaje, que se intensifica por la acumulación de citas de la comedia. Cfr. Lenfant (2003). 
representación trágica', como aparece, por ejemplo, en Luciano (Alex.12), o 'ayudar a montar una representación trágica', sentido que adopta aquí y en Them. 24.5. ${ }^{36}$ Hierón se encargaba de hacer correr la voz de que Nicias permanecía en su casa en vez de aparecer públicamente, porque trabajaba mucho por su pueblo, llevando una vida de sacrificios:

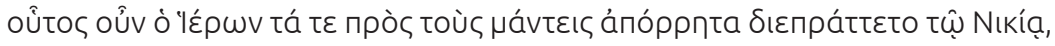

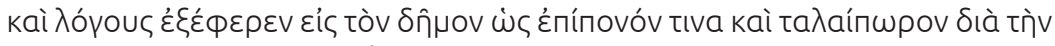

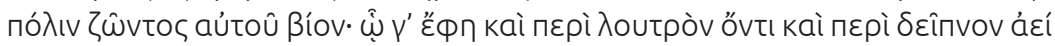

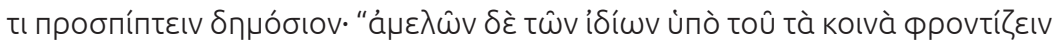

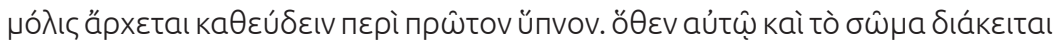

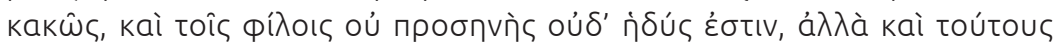

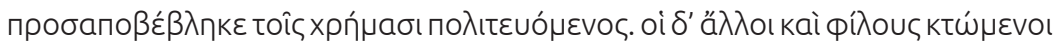

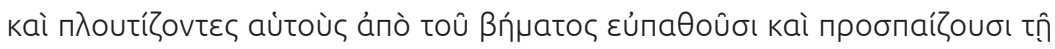

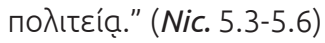

Este Hierón se encargaba por Nicias de los asuntos secretos con los adivinos y transmitía al pueblo el rumor de que éste vivía una vida sacrificada y sufrida a causa de la polis; decía que incluso cuando estaba en el baño y cuando estaba

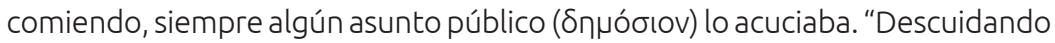
sus asuntos privados por preocuparse del bien común, apenas comienza a dormirse cuando otros ya tuvieron su primer sueño. Por eso, su cuerpo no se encuentra bien y no es amable ni dulce con sus amigos, sino que incluso los ha perdido, con su riqueza, sirviendo a la ciudad. Otros reciben beneficios de la tribuna, obteniendo amigos y enriqueciéndose y se burlan de la política".

Hierón no hace otra cosa que ayudar a componer el personaje de Nicias. Como un buen dramaturgo, concibe los discursos en torno a su figura, al punto que Plutarco cita sus palabras en discurso directo. Es evidente, por cierto, el tono exagerado del contenido de lo dicho (Nicias no puede comer ni dormir ni bañarse, ni tener amigos), lo que le sirve a Plutarco para enfatizar la ficcionalización llevada a cabo por Nicias.

Si pasamos a otros aspectos de la vida del general, advertiremos el mismo tratamiento. En el capítulo 6 Plutarco sugiere que incluso el alejamiento de Nicias de algunos hechos bélicos responde a un interés por mantener su popularidad; es decir, Nicias habría montado un personaje de cobarde, lo que no quiere decir que fuera un cobarde verdaderamente:

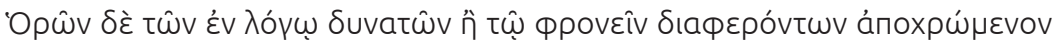

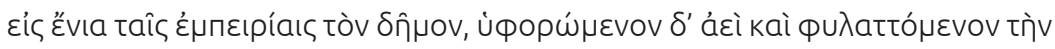

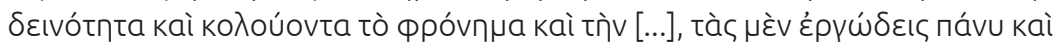

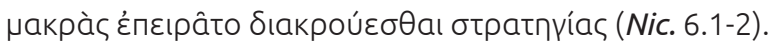

Viendo ("òpûv") Nicias que a veces el pueblo aprovechaba la experiencia de los hombres talentosos para los discursos o eminentes por su inteligencia, pero que siempre, desconfiando de ellos, se protegía de su inteligencia y rebajaba

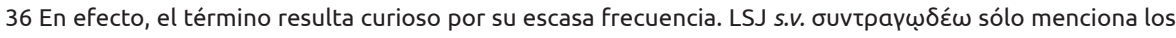
tres ejemplos que aquí referimos, mientras que el TLG tan solo añade una ocurrencia más, pero tardía (de Suda). El pasaje del Alejandro de Luciano describe también una puesta en escena, aunque de parte de un

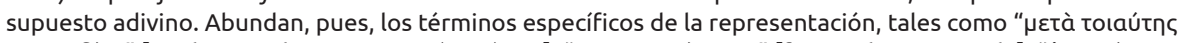

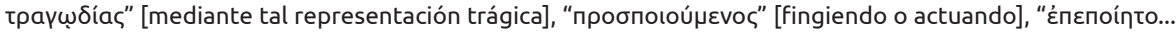

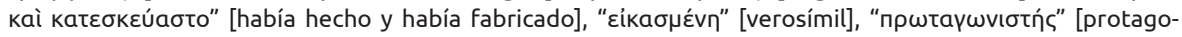
nista], "unxavâtaı" [maquina]. Tengamos en cuenta que las reflexiones en torno a la ficción, la verdad y la mentira son recurrentes en la literatura de la Segunda Sofística.
} 
sus aspiraciones y su fama [...]; por ello, [Nicias] trataba ("દ̇пعıрâto") de evitar las campañas militares muy difíciles y largas.

El término clave aquí es "ó@ $\tilde{\omega} v^{\prime}$ ", puesto que es el que nos describe la voluntad de Nicias de actuar de ese modo. En este mismo sentido, Plutarco relata más adelante que Nicias, ante los triunfos, en lugar de arrogarse la victoria, deja en

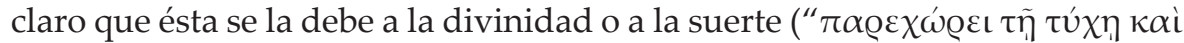

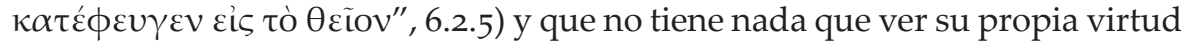

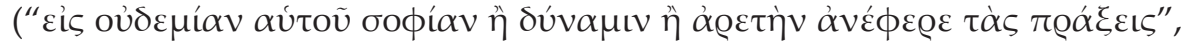
6.2.4), con lo que presenciamos nuevamente su decisión de construir una imagen de humildad ante el pueblo.

Como complemento de lo antedicho también es oportuno advertir la forma en que Plutarco alude a la teatralidad en diferentes pasajes de la biografía. Así, por ejemplo, en el capítulo 11, en la narración del ostracismo de Hipérbolo, hace una descripción de la masa como un espectador teatral, pues dice que el pueblo experimenta determinadas pasiones ante el hecho, siendo una de ellas la risa: "momentáneamente esto proporcionó al pueblo placer (†்ovìv)

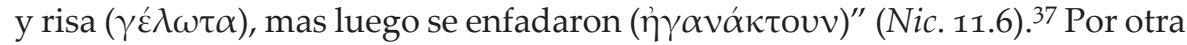
parte, en 21.1.6 se emplea el término " $\theta \varepsilon \alpha \tau \varrho \iota \kappa \tilde{\omega} \varsigma$ " para describir la manera en que Demóstenes se acerca con la flota para causar miedo a los enemigos en Siracusa: había preparado setenta y tres naves, cinco mil hoplitas, miles de lanzadores de jabalinas, arqueros y honderos, exhibición de armas, las insignias de las trirremes, contramaestres y flautistas. De más está decir que el tipo de teatralidad desplegada por Demóstenes se opone al de Nicias, lo que tiene su contrapartida política: mientras que Demóstenes está decidido a atacar, Nicias prefiere esperar, alimentando, dice Plutarco, la 'fama' de cobarde

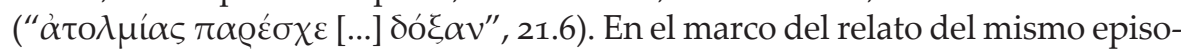
dio histórico, es sugerente también la mención a Eurípides luego de la derrota en Sicilia (29.3-4): Plutarco refiere que algunos de los atenienses capturados habían salvado sus vidas gracias a su conocimiento del tragediógrafo, porque los siracusanos eran sus máximos admiradores fuera de Atenas, de modo que se habían apiadado de las víctimas al recibir recitaciones de sus versos. ${ }^{38} \mathrm{La}$ teatralidad es, de hecho, protagonista de todo el final de la biografía, sobre todo en relación con la derrota en Sicilia. Ya en Tucídides se observa un tono trágico en la narración de los hechos, ${ }^{39}$ lo que Plutarco capitaliza en su propio planteo literario, a fin de dar homogeneidad a la descripción que viene construyendo del personaje de Nicias. Así pues, el biógrafo combina el tono dramático de la derrota (sobre todo entre los capítulos 24 y 26, donde detalla la cantidad de muertos, los gritos, las enfermedades padecidas, las terribles condiciones vividas) con la explicitación de que todo ello constituía una acción 'digna de

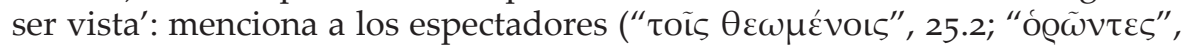

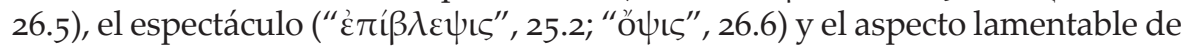

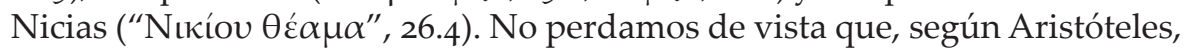
el espectáculo (ǒ $\downarrow \varsigma)$ es una de las seis partes de la tragedia (cfr. Po. $1450 a 10$

37 Acerca de lo perjudicial de estas pasiones exaltadas por el arte, cfr. Pl., R. II 379; X 598c; X 605; X 605b; contra, Aristóteles, Po. 1449b 24-28; 1453 b 11.

38 Cfr. Crass. 33.2-3, donde hay también una alusión a la obra de Eurípides. Se dice que la cabeza de Craso fue llevada ante el rey de los partos por un actor trágico que interpretaba el papel de Ágave en Bacantes, recitando a la vez unos versos de la tragedia (1169-1171 y 1178-1179).

39 Cfr. Th. VII.70.1-72.2, D. S. XIII 15.3-17.5. Westlake (1941), Blaiklock (1944), Braund (1993), Rood (2002:195), Burns (2012). 
y 1450b16-21) y que tiene por función cautivar el alma del público, esto es, generar su interés (" $\psi v \chi \alpha \gamma \omega \gamma \iota \kappa o ̀ v ") 4^{40}$, lo que claramente se aplica a este pasaje.

En vinculación con lo ya expuesto, es posible mencionar un último episodio dramático protagonizado por Nicias: en uno de los pocos ejemplos de discurso directo que hallamos en la biografía, Plutarco lo hace postrarse ante Gilipo

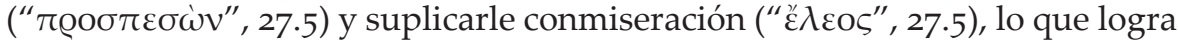

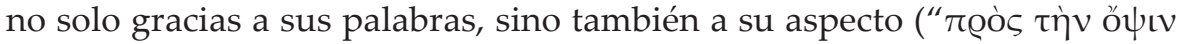

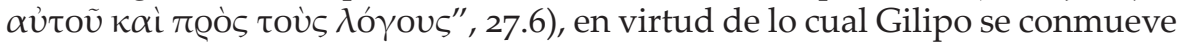
("ع̌ $\pi \alpha \theta \varepsilon$ ", 27.6). Plutarco señala que incluso después de muerto Nicias es objeto de espectáculo, pues su cuerpo, junto con el de Demóstenes, yacen exhibidos

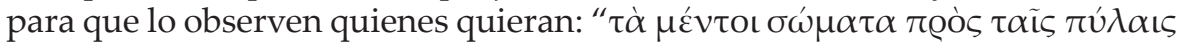

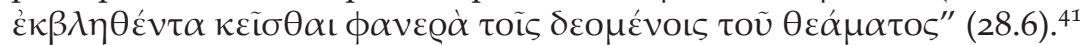

En suma, mientras que en la Vida de Alcibíades la teatralidad se basa en un histrionismo exagerado, en artimañas y en un gran despliegue verbal (y engañoso), en la Vida de Nicias observamos que la teatralidad consiste en lo contrario: la creación de un personaje tímido y reservado. En ambos casos, no obstante, Plutarco lo entiende como un procedimiento deliberado de los líderes atenienses a fin de tener éxito en sus carreras políticas, y arma su entramado narrativo en función de destacar dicho procedimiento.

Pasamos ahora a analizar la Vida de Pericles. Hallamos aquí elementos similares a los ya vistos en Alcibíades y Nicias, aunque expresados de manera distinta. En primer lugar se advierte la intención premeditada del personaje de mantener su imagen pública, basándose ésta (a diferencia de las otras biografías estudiadas) en la seriedad que emana de la virtud. Es decir, no se trata ni del patetismo por exceso ni por defecto, tal como vimos en los ejemplos anteriores, sino de la configuración de una personalidad moderada y, por ende, en el medio entre ambos extremos, según veremos. Asimismo, a diferencia de Alcibíades y de Nicias, quienes, según comprobamos, basaban sus personajes en características que les venían dadas de manera natural, el personaje que Pericles forja ante el pueblo parece contrario (o no del todo acorde) a su forma de ser, al menos a partir de lo que es posible deducir de algunas anécdotas. En el capítulo 7 de la biografía Plutarco señala abiertamente que la conyuntura llevó a Pericles a abocarse al pueblo: Arístides había muerto, Temístocles había caído en desgracia, Cimón pasaba largos períodos fuera de Grecia debido a las campañas militares, de modo que Pericles aprovechó esta situación para consagrarse ante el pueblo, "habiendo elegido, en lugar de a los ricos y pocos, los asuntos de los muchos y pobres contra su propia naturaleza, que era poco popular" [ $\dot{\alpha} v \tau i$

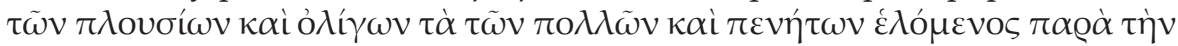

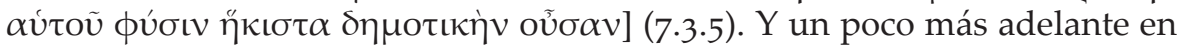
la biografía es donde se dan más detalles respecto del 'papel' que interpreta Pericles para agradar a las masas:

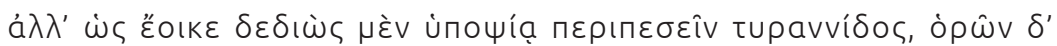

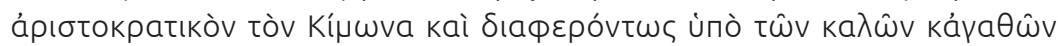

40 También en el pseudo platónico Minos se define a la tragedia como "la parte de la poesía que más deleita

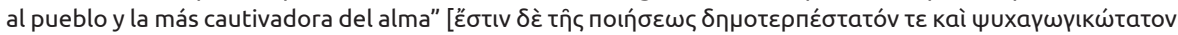

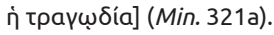

41 Tengamos en cuenta además que Plutarco apela en esta biografía al recurso de la cohesión léxica a fin de enfatizar el grado de apariencia con el que se sustenta el personaje en cuestión, lo que se observa en el

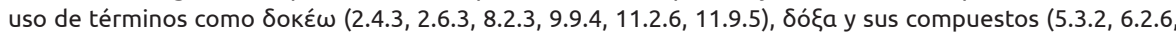

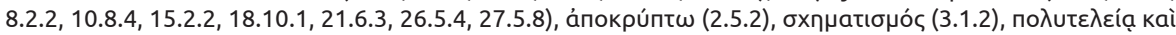
xápıtı (3.2.5), que aparecen en general concentrados en unos pocos capítulos. Cfr. Sapere (2014:148-149). 


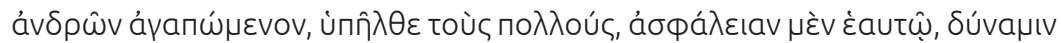

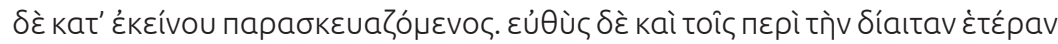

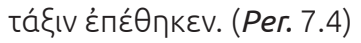

Al parecer tenía miedo a la sospecha de que aspiraba a la tiranía y, por otro lado, veía a Cimón con los aristócratas y especialmente querido por los hombres de noble condición; así que se refugió en el pueblo, preparándose su propia

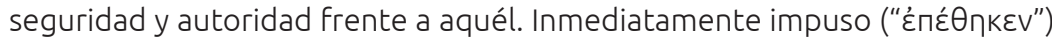
un carácter distinto ("غ̇tépav tá ııv") a su forma de ser habitual. (Per. 7.4)

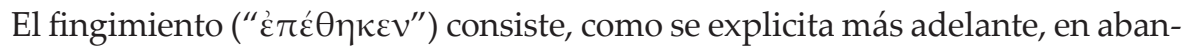

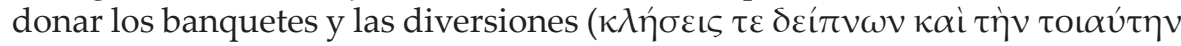

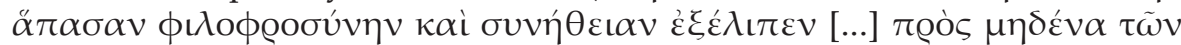

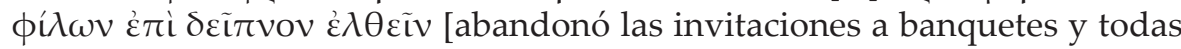
las reuniones y encuentros del estilo [...] no fue al banquete de ningún amigo]: Per. 7·5·3-5), y exhibirse ( $\varepsilon \omega \varrho \tilde{\alpha} \tau o)$ solamente en el camino que conduce al

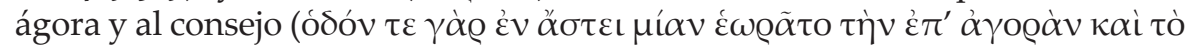

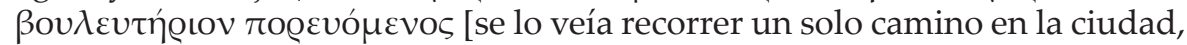
el que va al ágora y al Consejo]: Per. $7 \cdot 5 \cdot 2-3)^{42}$, acercándose al pueblo sólo por

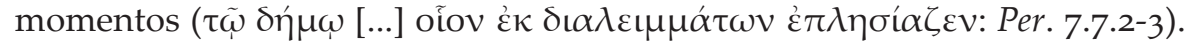
Así pues, el retrato que desea erigir es el de un hombre serio, sereno y virtuoso. Se cuenta, por ejemplo, que ni siquiera en los funerales de sus familiares

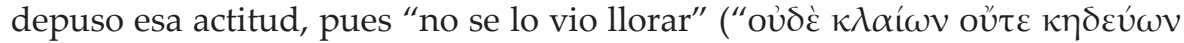

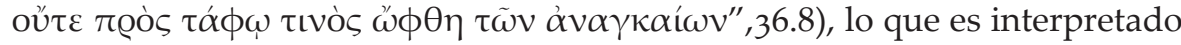

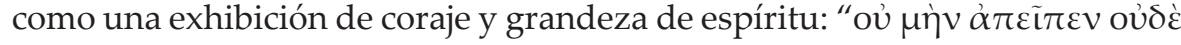

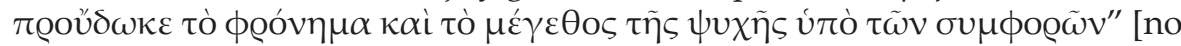
abandonó ni traiciónó su coraje y grandeza de espíritu por las desgracias] (Per. 36.8.1-3). Detengámonos en la retórica de esta última frase: el uso de los

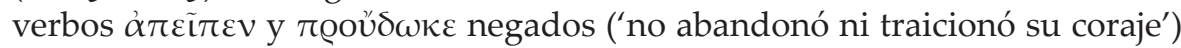
nos confirma la idea de que la reacción natural de cualquiera hubiera sido la contraria, esto es, dejarse llevar por el dolor; Pericles, en cambio, se esfuerza una vez más por mantener su imagen valerosa e imperturbable. Para Plutarco, entonces, Pericles ostenta una pose, en la medida en que busca mostrar un tipo

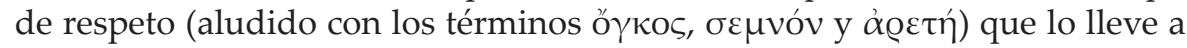
obtener fama (ז@ò $\delta o ́ \xi \alpha v)$.

Otro ejemplo de que Pericles basa su imagen pública en una actuación es la anécdota que se cuenta en 7.6: la única vez que decidió mostrarse en una celebración familiar fue en el casamiento de su primo Euriptólemo, aunque sólo permaneció hasta el brindis (" $\left.\chi \chi \chi \iota \tau \tilde{\omega} \nu \sigma \pi 0 \nu \delta \tilde{\omega} v^{\prime \prime}\right)$, momento en

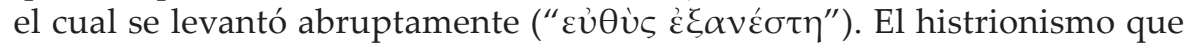
implica brindar, levantarse de manera inmediata e irse da cuenta de que su intención era precisamente llamar la atención: que los demás vieran que su participación en el festejo estaba restringida a un breve lapso de tiempo y que tenía la capacidad de moderarse y partir a tiempo, mientras los demás se quedaban celebrando.

En el capítulo 5 de la biografía hallamos una descripción de Pericles en donde los únicos rasgos que se consideran son los exteriores, gracias a lo que confirmamos todos los detalles de su personaje: la forma de hablar, elevada, 'libre de

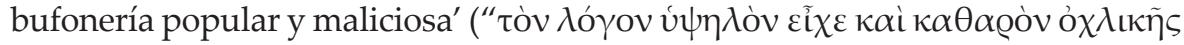

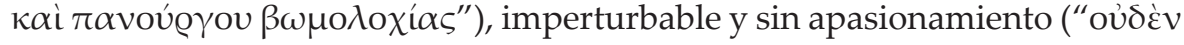

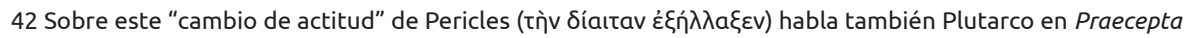
gerendae reipublicae 800 c1-6 


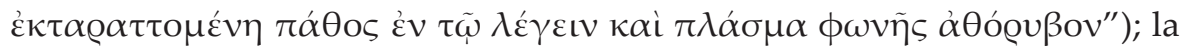

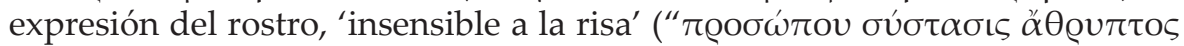

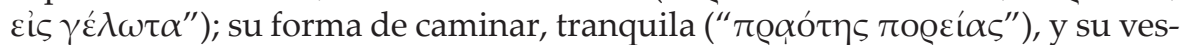

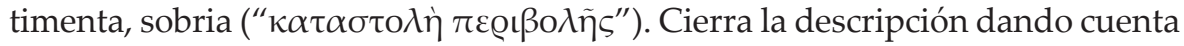
del efecto de admiración que todo ello generaba en el público: "cuantas cosas similares dejaban maravillosamente perplejos a todos" [ö $\sigma \alpha \tau o \iota \alpha \tilde{v} \tau \alpha$ Tó $v \tau \alpha \varsigma$ $\theta \alpha v \mu \alpha \sigma \tau \tilde{\omega} \varsigma \dot{\varepsilon} \xi \dot{\varepsilon} \pi \lambda \eta \tau \tau \varepsilon]$. Se trata, pues, de una caracterización de todos los rasgos actorales: la voz, la forma de hablar y caminar, la gestualidad e incluso el disfraz.

Ya mencionamos la moderación de su discurso. En efecto, la forma cuidada de

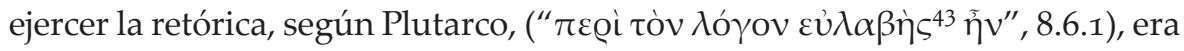
una pieza clave para la imagen pública de Pericles, pues gracias a esto lograba manejar a su pueblo:44

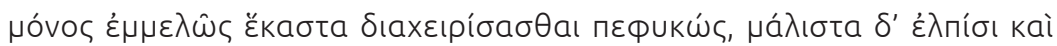
Фóßoıc

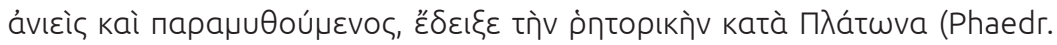

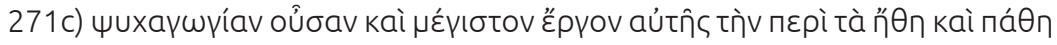

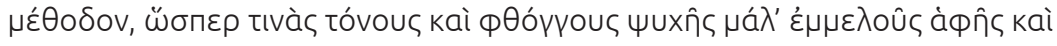

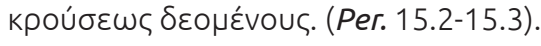

Solo él era apto por naturaleza para manejar cada cosa de manera conveniente, principalmente, reduciendo la insolencia [del pueblo] y suavizando y calmando su mal humor, [valiéndose] de esperanzas y miedos, como de timones. Y así mostró que la retórica, según Platón, ${ }^{45}$ es conducción de las almas ("uuxaywríav") y que su obra más grande es el adoctrinamiento de los caracteres y las pasiones ("tà n̋Өn kaì ná $\theta \eta$ "), como si fueran ciertos tonos y sonidos del alma necesitados del toque de un instrumento adecuado.

Ya mencionamos previamente que Aristóteles describe el espectáculo teatral con el adjetivo $\psi v \chi \alpha \gamma \omega \gamma \iota \kappa o ́ \varsigma$ (Po. 1450b17.), fácilmente asociable con la 'conducción de almas' ( $\psi v \chi \alpha \gamma \omega \gamma$ í $\alpha$ ) que lleva a cabo Pericles mediante el uso de la palabra. ${ }^{46}$ Cabe aclarar que el empleo de la retórica, a diferencia de lo que habíamos visto en Alcibíades, no está al servicio del engaño sin escrúpulos, sino que está en función de convencer a partir de la moderación y la sobriedad, dado que estas son, ni más ni menos, las cualidades del propio Pericles y las que desea transmitir en su discurso. ${ }^{47}$

43 Tomamos el sentido metafórico que ofrece LSJ, "undertaking prudently, discreet, cautious".

44 Para el análisis de la relación de Pericles con el pueblo, cfr. Fornara; Samons (1991:69-60), Stadter (1989:112ss.), Saïd (2005:14ss.) y Pébarthe (2010). Dice Saïd (2005:14): "In the Life of Pericles the people is

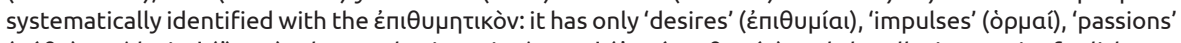

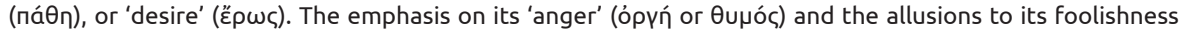

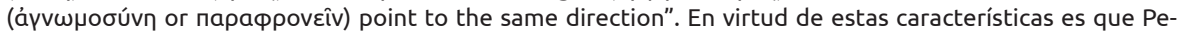
ricles construye su imagen pública. Sobre la importancia de la retórica en la Vida de Pericles, cfr. Stadter (1987), Azoulay (2001:202 y 205).

45 Cfr. Phdr. 271c.

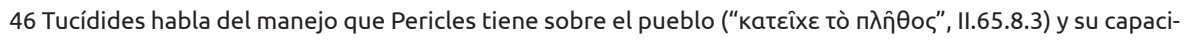
dad de transmitirles temor o confianza de acuerdo a las necesidades (cfr. II.65.9).

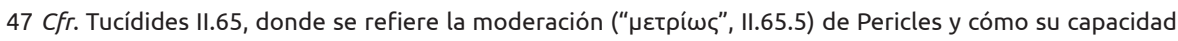

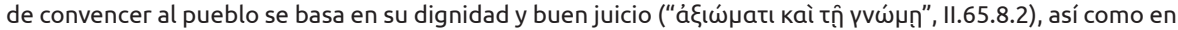

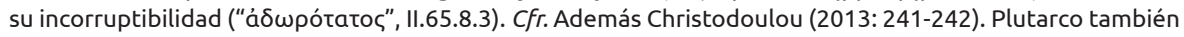
considera que Pericles es un hombre virtuoso, pero no deja de enfatizar la composición de personaje que lleva a cabo. 


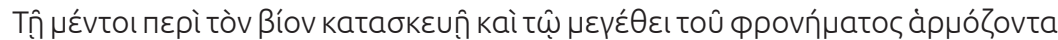

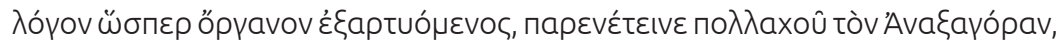

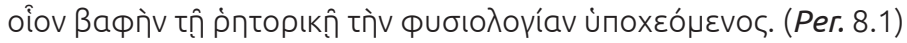

Preparando su discurso, como instrumento que se ajusta, ciertamente, con su modo de vida y con la grandeza de su espíritu, intercalaba en muchos lugares a Anaxágoras esparciendo en la retórica el estudio de la naturaleza como un tinte.

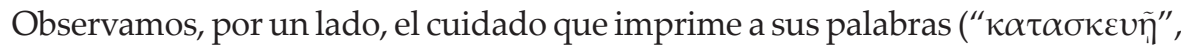

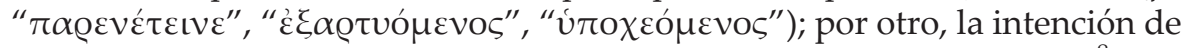
hacer corresponder (" $\alpha \varrho \mu$ ó $\zeta o v \tau \alpha$ ") el discurso con la forma de vida, ${ }^{8}$ esto es, componer un personaje creíble (y aceptable para la masa) para así llegar a convencer. Respecto de su habilidad retórica es ilustrativa la anécdota en la que Tucídides, hijo de Melesias, al ser preguntado sobre quién era mejor

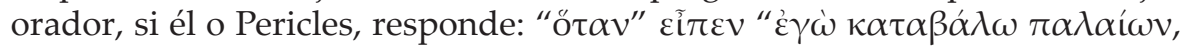

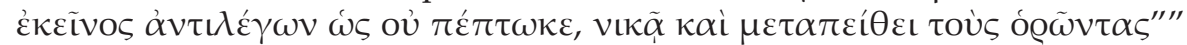
(8.5) ["cuando", dijo, "lo derribo en el combate, él, negando que cayó, vence y convence de ello a los espectadores"]. Podemos observar, más allá de la capa-

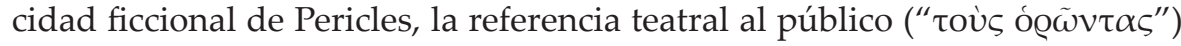
que se deja convencer (" $\mu \varepsilon \tau \alpha \pi \varepsilon i ́ \theta \varepsilon \iota^{\prime \prime)}$. Pericles es claramente un actor pero, sobre todo, un buen director teatral.

Las medidas llamadas 'demagógicas', como la construcción de edificios y monumentos, las coregías y los espectáculos (tema desarrollado en los capítulos 12 a 14 de la biografía) también forman parte de esa imagen pública elaborada por Pericles, aunque en este caso es la ciudad la que se disfraza y se exhibe. Por tal motivo, en los pasajes en los que se narra la edificación de las obras públicas, es recurrente un tipo de vocabulario relacionado con lo 'espectacular' (tanto como tecnicismo como en su valor etimológico): se compara

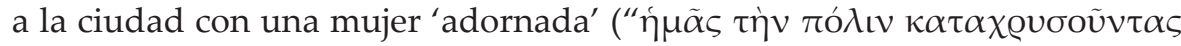

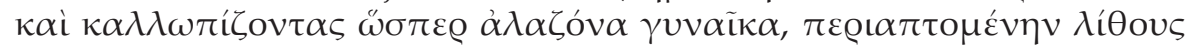
$\pi 0 \lambda v \tau \varepsilon \lambda \varepsilon \varepsilon \varsigma^{\prime}$ ", 12.2), se menciona la 'fama' de Atenas debido a poseer estas

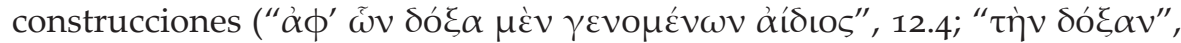

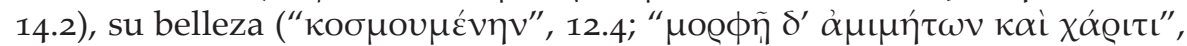

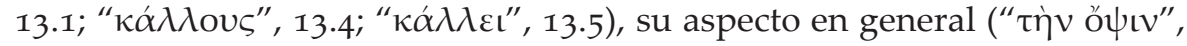

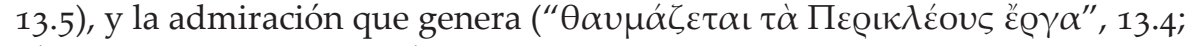

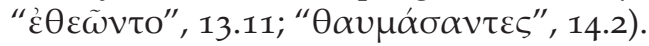

Para cerrar, no podemos dejar de señalar el efecto cohesivo que aportan las alusiones al teatro ático a la largo de la biografía. La mayoría de ellas son citas cómicas en las que se expresa una burla hacia el personaje, a las que Plutarco no suele dar crédito, por el componente injurioso y mendaz: aparecen, citadas textualmente, burlas por el tamaño de su cabeza (de parte de Cratino, Teleclides y Éupolis, 3.1-4, 13.10), por su relación con Aspasia (lo injurian Cratino, Éupolis y Aristófanes, en 24-9-10 y 30.4), por el retraso en las construcciones (Cratino, 13.8) y por los gastos de dinero (Teleclides, 16.2), entre las críticas más importantes. La aparición de estas citas en el texto nos transporta a la Atenas clásica en la que circulaban dichos discursos y, por ende, nos instruye acerca del peso de las representaciones teatrales de la época, en tanto que el propio Plutarco, incluso sin estar de acuerdo con la imagen que ofrecen de Pericles, se ve en la obligación de exhibirlos.

48 Idea que esboza Plutarco en el Prólogo de la biografía: las acciones que surgen de la virtud despiertan

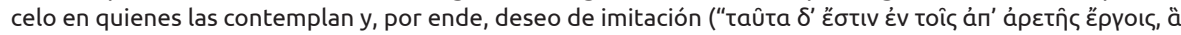

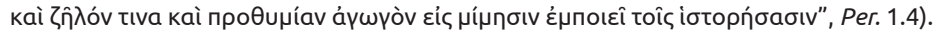




\section{El caso puntual del teatro cómico: entre Atenas y Roma}

En virtud de lo ya expuesto, creemos que es preciso destinar un párrafo aparte al caso concreto de la comedia, dada su particular preeminencia en la vida cívica ateniense, lo que nos servirá además para reflexionar sobre la distancia que existe entre el contexto social y político de los personajes retratados por Plutarco y el del propio autor. En efecto, la comedia ática jugaba un papel importante en el seno de la polis: el ataque a las personalidades e instituciones de la época, la burla y el escarnio en tono cómico formaban parte de un dispositivo de la democracia que servía para contener los excesos de los poderosos. El discurso teatral cómico reflexiona así sobre la política pero siempre desde una mirada crítica, que tergiversa y distorsiona las normas establecidas, lo que permite equilibrar, de algún modo, los posibles abusos de la clase gobernante ${ }^{49}$. Esta dinámica es completamente impensada para la Roma imperial de Plutarco, en la que no hay lugar para el disenso ${ }^{50}$. Los autores de la época son conscientes de la forma cuidada en la que deben expresarse respecto de los poderosos, de quienes dependen y a quienes deben, en muchos casos, el éxito de sus carreras ${ }^{51}$. Plutarco no es la excepción a ello, de modo que sus opiniones acerca del teatro ateniense deben ponerse en relación no solo con su planteo estético o moral, sino también con su actitud frente a la realidad política que le toca vivir. Pensemos que Plutarco había trabado amistad con miembros de la elite y personalidades influyentes del imperio romano (tales como L. Mestrio Floro y Q. Socio Senecio, a quienes menciona en sus escritos) y ocupó cargos públicos de relevancia (fue magistrado en Queronea y sacerdote de Apolo en el Templo de Delfos, representó a su pueblo natal en varias misiones al extranjero, fue nombrado por Trajano procurador de Iliria y se cree que fue nombrado por Adriano procurador de Acaya). Así pues, como personalidad reconocida en los círculos de poder de la Roma de los primeros siglos, Plutarco debe mantener y defender un discurso político moderado, lo que contrasta claramente con la esencia combativa del discurso cómico ateniense. La crítica que ejerce el autor acerca de las perniciosas mentiras sobre los poderosos que engendra la litertura en general y el teatro en particular se fusiona a la perfección, entonces, con la ideología de su época.

\section{El paralelo con Esparta}

Dijimos más arriba que la forma en que Plutarco describe la teatralidad de los actos de gobierno de Nicias, Alcibíades y Pericles es una muestra de cómo entiende nuestro autor la dinámica política en Atenas. En este sentido, de lo ya analizado es posible colegir que, para Plutarco, los ciudadanos atenienses están inmersos en un ambiente en el que el espectáculo tiene una fuerte presencia y probablemente sea esto lo que lleve a los líderes políticos a echar mano de los recursos teatrales a fin de lograr sus objetivos. El histrionismo de Alcibíades es su cara más visible, mientras que los personajes compuestos por

49 El tema ha sido ampliamente debatido. Cf. por ejemplo Gomme (1938), Carrière (1983), Bowie (1996), Olson (2010), García Soler (2013).

50 Referimos al artículo de Xifra (2019) sobre al disenso en la comedia aristofánica, para pensar el contraste con la actitud de Plutarco como intelectual ante el poder. Se puede contrastar esta postura con la defensa de la òjóvoı que hace Plutarco en su Praecepta gerendae reipublicae.

51 Sobre la prudencia respecto de las opiniones políticas en Plutarco cf. por ejemplo Flacelière (1963), Barrow (1967), Jones (1971), Silva (2005, 2006, 2007), Ash (2008), Desideri (2012). En el marco general de los autores de la Segunda Sofística, cf. por ejemplo Bowersock (1969), Bowie (1970), Alcock (1993), Swain (1996), Schmitz (1997), Goldhill (2001), Stadter \& Van der Stockt (2002), Borg (2004), Whitmarsh (2005). 
Nicias y Pericles, que ostentan moderación, no dejan de estar concebidos para una representación pública. El protagonismo del fenómeno teatral es, pues, la condición de posibilidad de dicha práctica política, de suerte que debemos entender también que hay un público espectador que tiene las competencias para decodificar la forma en que proceden estos políticos 'actores'. En este punto nos parece pertinente llevar a cabo la comparación con Esparta, dado que allí la práctica teatral no se desarrolla del mismo modo, siendo el propio Plutarco quien reflexiona sobre ello en su obra. El contraste que establezcamos nos resultará de utilidad para la formulación de las conclusiones finales.

De la lectura de las Vidas Paralelas queda claro que, a diferencia del contexto ateniense, Esparta parece ajena a los encantamientos y ficciones que brinda el teatro y, en general, todo tipo de arte. Así, por ejemplo, en Licurgo 6.3 Plutarco describe el lugar en el que se celebran las asambleas entre los lacedemonios, completamente despojado de adornos, pues se considera que esto perjudica la buena deliberación, dado que los hombres, en lugar de estar concentrados en la tarea, se distraen mirando las estatuas y las pinturas que hay en los proscenios de los teatros:

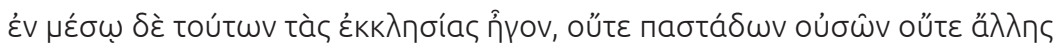

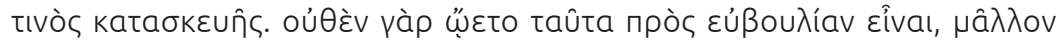

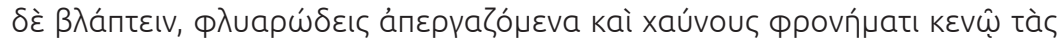

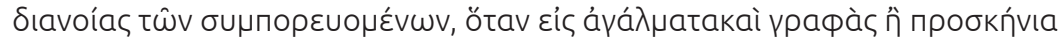

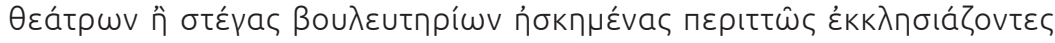

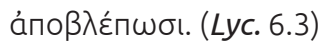

En medio de estos lugares llevaban a cabo las asambleas, sin que hubiera pórticos ni ninguna otra construcción. Pues [Licurgo] consideraba que estas cosas no ayudaban al buen juicio sino que más bien lo dañaban, haciendo que las reflexiones de los asistentes se vuelvan tontas y frívolas, a causa de un pensamiento vacío, cuando, estando reunidos en asamblea, miran hacia las estatuas y dibujos que adornan los proscenios de los teatro o los techos de las salas de consejo.

Es evidente que semejante descripción responde a la imagen estereotipada de austeridad y sencillez lacónicas, con la que sin lugar a dudas Plutarco simpatiza..$^{52}$ En este caso, el lugar común le sirve al biógrafo para criticar por contraste la artificiosidad y teatralidad atenienses. Otra anécdota vinculada con esto la hallamos en la Vida de Agesilao, en donde se da cuenta del desdén del rey espartano hacia los actores:

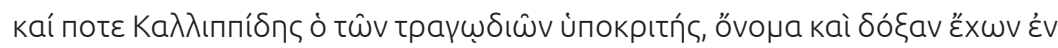

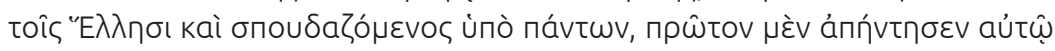

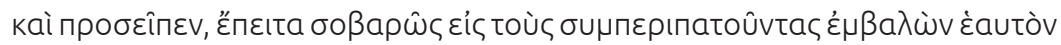

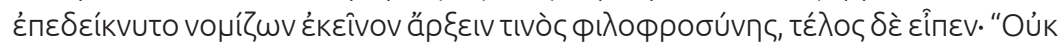

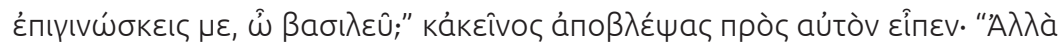

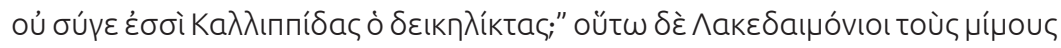

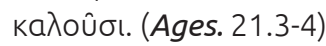

Una vez, Calípides, el actor de tragedias, que tenía renombre y fama entre los griegos y era respetado por todos, en un primer momento se encontró

52 Acerca del mirage spartiate (Ollier, 1933) cfr. Rawson (1969), Tigerstedt (1974), Whitby (2002), Castelnérac (2008), Fornis (2012), Olinski (2016), entre otros. Sobre la mirada positiva de Plutarco respecto de Esparta y en particular de la Esparta de Licurgo, cfr. Schoeck (1956), Liebert (2009), Rocha (2014), entre otros. 
con él [sc. Agesilao] y lo llamó; luego, dirigiéndose pomposamente hacia los que se encontraban con él se exhibió creyendo que éste comenzaría con algún elogio, y finalmente dijo: “¿No me reconoces, oh rey?" Aquel, tras

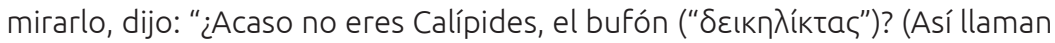
los lacedemonios a los actores). ${ }^{53}$

El término $\delta \varepsilon \iota \kappa \eta \lambda i ́ k \tau \alpha \varsigma$ parece aludir a un tipo de actor más bien cómico o burlesco, de modo que la respuesta de Agesilao tenía la intención de rebajar a Calípides, quien se sentía muy seguro por su fama como actor de tragedias. Debemos concluir, además, que Agesilao no respeta las interpretaciones teatrales en general (de allí su desprecio por Calípides y su despliegue de histrionismo), lo que queda corroborado con la anécdota que Plutarco narra a continuación en la biografía: cuando cierta vez fue invitado a escuchar a un imi-

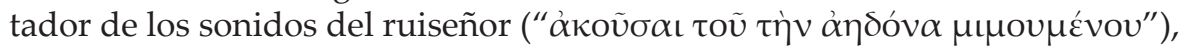
Agesilao se negó, dando como respuesta "Ya he escuchado al ruiseñor mismo" [Aủ̃ $\tilde{\alpha} \varsigma \alpha \ddot{\kappa} \kappa o v \kappa \alpha] .{ }^{54}$

En Lisandro 21.4 Plutarco señala que éste no se comportaba de modo de

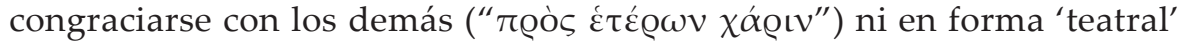

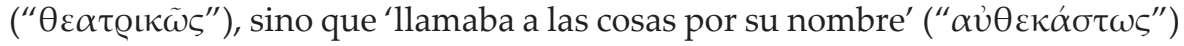
por el bien de Esparta. El adjetivo del que deriva el adverbio $\alpha \hat{v} \theta \varepsilon \kappa \alpha ́ \alpha \tau \omega \varsigma$ quiere decir según LSJ "one who calls things by their right names, downright, blunt" y para referirse al estilo de una persona, "inartificial, plain" (cfr. LSJ s.v. $\alpha u ̉ \theta \varepsilon ́ \kappa \alpha \sigma \tau o \varsigma)$. Más allá de la descripción estereotipada del espartano como sencillo y sin artificio, es relevante, para lo que intentamos probar, el uso del adverbio $\theta \varepsilon \alpha \tau \varrho \iota \kappa \tilde{\omega} \varsigma$ no solamente como alusión puntual al teatro, sino como un juicio de valor respecto de una conducta impropia para el general espartano.

En Licurgo 19.2 también hay una anécdota que deja en evidencia el gusto de los espartanos por la expresión simple y concisa (" $\dot{\alpha} \pi^{\prime} \varepsilon \dot{v} \tau \varepsilon \lambda$ oṽ $\varsigma \alpha \alpha \grave{i}$ ỏ $\left.\lambda \hat{\gamma} \gamma\right\rceil \varsigma$

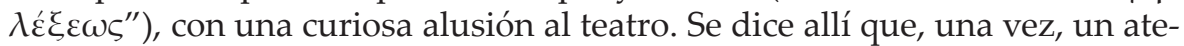
niense criticó al rey Agis por las espadas espartanas, que son cortas y suelen

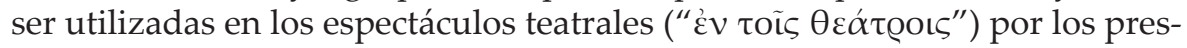
tidigitadores, que se las tragan con facilidad. A ello Agis responde: "nosotros, sin embargo, alcanzamos muy bien a los enemigos con estas dagas" ["K $\alpha \grave{i} \mu \eta \dot{\nu}$

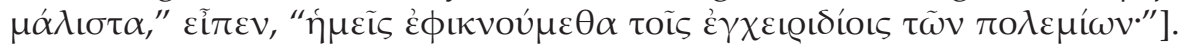
Más allá de la ya mencionada descripción de la proverbial austeridad lacónica, creemos que es posible interpretar también una contraposición entre lo teatral y lo 'real', dicotomía que pone a los atenienses de un lado y a los espartanos del otro, respectivamente: el ateniense se burla de que es posible, en el marco de una representación, tragar una daga espartana con completa facilidad; el espartano, por su parte, desestima el valor de la puesta en escena y solo otorga importancia a la efectividad de las dagas en batalla. Esta idea que contrapone la acción teatral (ficcional) y la acción bélica (real) también es expresada en $D e$ gloria Atheniensium (Moralia 348f4-349a4):

53 La anécdota parece del gusto de Plutarco, pues se halla también en Moralia 212e. La exagerada forma de actuar de Calípides era proverbial: Aristóteles refiere que Minisco de Eubea lo llamaba 'mono' por

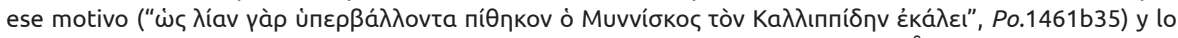

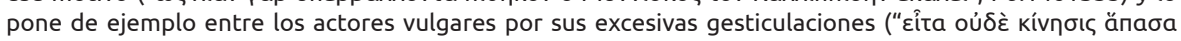

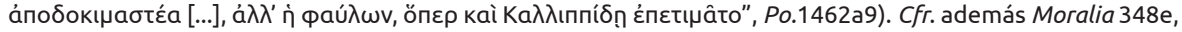
X. Smp. 3.11 y Csapo (2002), Milanezi (2004), Hall (2007:283), Stanford (2014:6). Calípides es mencionado también en el regreso teatral de Alcibíades a Atenas (Alc. 32.3).

54 Cfr. también Moralia 191b, 212e y 231c y Lyc. 20, donde vuelve a referirse la anécdota. 


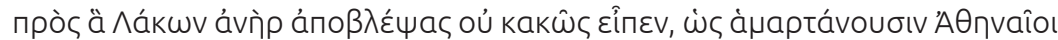

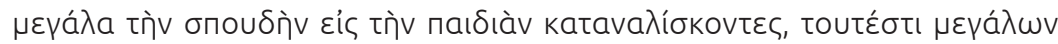

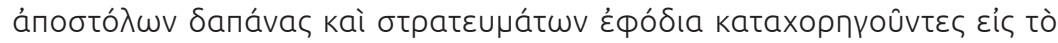

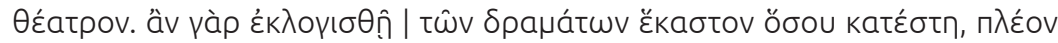

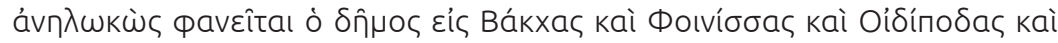

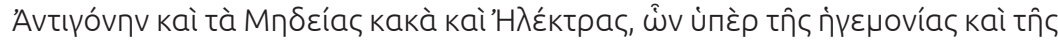

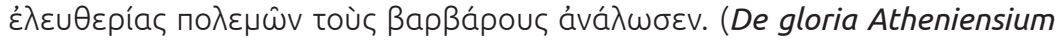
348f4-349a4).

En cuanto a estas cosas [los preparativos del teatro], un espartano, tras verlas, dijo no erróneamente que los atenienses se equivocan grandemente al dedicar sus esfuerzo en diversiones, esto es, gastando sumas de dinero para el teatro en grandes misiones y provisiones para expediciones militares. Pues si se calcula a cuánto llega cada uno de los dramas, se verá que el pueblo ha gastado más en Bacantes, Fenicias, Edipos y Antígonas y en las desgracias de Medea y Electra, que en lo que gastaron en sus guerras con los bárbaros por la hegemonía y la libertad. ${ }^{55}$

En Quaestiones conviviales 710f5 se vuelve a expresar este pensamiento con una anécdota similar: cuando un espartano observa el afán de los preparati-

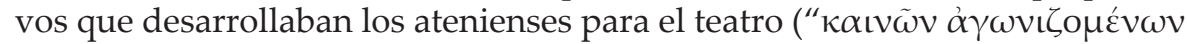

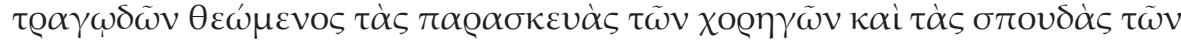

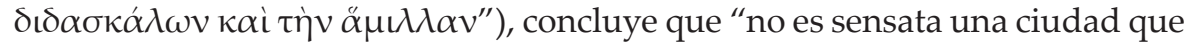

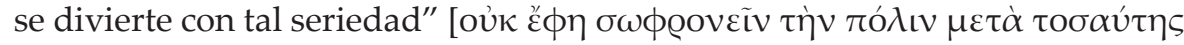

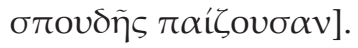

Para culminar este apartado es preciso volver a Atenas. Lo que se desprende del contraste entre ambas ciudades tal como lo muestra Plutarco es que Atenas era un terreno fértil desde el punto de vista cultural y social para que se llevara a cabo la articulación entre teatro y política que hemos observado en las biografías: allí como en ninguna otra ciudad del mundo griego el teatro tiene un lugar central, donde reside la condición de posibilidad para que la política también adopte sus formas. Con esto no queremos decir que Plutarco desconozca la importancia de la actividad teatral en otras ciudades del mundo griego, incluso en Esparta, a la que pusimos como ejemplo. Sí creemos que el biógrafo tiene una visión idealizada del fenómeno cultural y artístico ateniense (su esplendor, su despliegue), del mismo modo que guarda una visión estereotipada de la austeridad espartana, a la que admira, en la medida en que se adapta a su planteo filosófico, según hemos comentado. ${ }^{56}$ Esta mirada, precisamente por su carácter estereotipado, es la que le permite esbozar de manera patente su crítica moral a los artilugios de los políticos atenienses y su admiración por la honestidad y naturalidad espartanas.

55 Acerca de las cuantiosas sumas de dinero gastadas por los atenienses para las representaciones teatrales, cfr. Csapo; Slater (1995:141), Slater (2007) y Wilson (2008).

56 Tengamos presente que la bibliografía más actual tiende a rehuir la mirada atenocéntrica de los fenómenos culturales, cambio de enfoque que ha sido útil para comprobar el desarrollo de las artes en general y del teatro en particular en distintas ciudades del mundo griego. Autores como Revermann (1999; 2011:21, 6872), Taplin (1993, 1999), Wilson (2000:279-302), Csapo (2004) y Hall (2006:29), entre otros, se han dedicado al estudio de la recepción del teatro griego, gracias a lo que se ha probado con solidez su protagonismo fuera de Atenas. Plutarco, como vimos, le adscribe al teatro ateniense un esplendor y protagonismo singulares. 


\section{Conclusiones}

En el recorrido textual que hemos ofrecido pudimos comprobar que Plutarco decodifica la política en los términos de la dinámica teatral. Esto quiere decir que, según su visión, no sólo es el teatro el que influye desde el escenario en la audiencia para criticar o elogiar a las figuras de renombre, sino que además dichas figuras se valen de la teatralidad para hacer política. Pericles, Nicias y Alcibíades son para Plutarco (cada uno con su estilo) un ejemplo de 'actuación' al servicio de sus intereses políticos, pues la descripción que ofrece de ellos permite interpretar que han creado personajes y dispositivos teatrales que llegan al $\delta \tilde{\eta} \mu o \varsigma$ en tanto espectador. El análisis acerca del fenómeno teatral en Esparta nos ha permitido entender que esta forma de hacer política solo cobra sentido en una sociedad atravesada profundamente por los efectos del teatro, tanto para los políticos que toman los recursos propios de la mímesis teatral como para los ciudadanos en general, acostumbrados a verse interpelados por el fenómeno dramático.

Hemos visto además que Plutarco, sobre la base de sus opiniones filosóficas y morales de raíz platónica, reprueba las mentiras y exageraciones del teatro, y es así como su crítica se traslada a los generales retratados, que apelan a las mismas manipulaciones y engaños de los tragediógrafos, comediógrafos y poetas en general. En última instancia, puede interpretarse también que en este planteo subyace una opinión negativa de los mecanismos de la democracia ateniense, sobre todo en lo que respecta a la relación entre los líderes y el pueblo. Plutarco, dedicado en su obra biográfica a exponer modelos de virtud para sus lectores, se vale de un entramado textual complejo y cohesivo (uso de vocabulario específico, metáforas, alusiones y citas textuales, según vimos) para poner en evidencia los procedimientos teatrales empleados por los grandes políticos de Atenas a fin de que dicha evidencia sirva no solamente a los fines de una reconstrucción histórica sino también, y fundamentalmente, a los efectos de lograr un enriquecimiento moral, que demanda una reflexión acerca de los artilugios y engaños que son constitutivos de la actividad democrática. Tales opiniones y reflexiones deben leerse, además, en el contexto social y político de nuestro autor: en tanto intelectual griego supeditado al poder central de Roma debe adoptar un discurso sobre el poder que bregue por la moderación y la concordia, a partir de lo cual cobra más sentido su visión negativa respecto de las mentiras y exageraciones del discurso teatral. 


\section{Q Bibliografía}

»Aguilar, R. M. (1984). "Plutarco, el teatro y la política”, EClás. 26, 421-426.

" Alcock, S. (1993). Graecia Capta: the Landscapes of Roman Greece. Cambridge: University Press.

"Arendt, H. (1961), "What is Feedom?". En: Between Past and Future. Six Exercises in Political Thought. New York: The Viking Press, 143-172.

" Ash, R. (2008). "Standing in the Shadows: Plutarch and the Emperors in the Lives and Moralia". En Nikolaidis, A. (ed.). The Unity of Plutarch's Work: 'Moralia' Themes in the 'Lives', Features of the 'Lives' in the 'Moralia'. Berlin: Walter de Gruyter, 557-575.

"Atkinson, J. E. (1995). "Nicias and the fear of failure syndrome", AHB 9.2, 55-63.

»Azoulay, V. (2001). "Périclès, une Vie en clair-obscur. L'inaccessible transparence du politique", Hypothèses 2001/1, 201-209.

"Baron, C. (2017). "Comedy and History, Theory and Evidence in Duris of Samos". Histos Supplement 6, 211-239.

" Barrow, R. H. (1967). Plutarch and His Times. London: Chatto \& Windus.

" Bers, V. (1994). "Tragedy and Rhetoric". En: Worthington, I. (ed.), Persuasion: Greek Rhetoric in Action. London-New York: Routledge, 176-195.

» Blaiklock, E. (1944). "Tragedy at Syracuse", G\&R13 (38-39), 83-85.

"Bloedow, E. (1990). "'Not the Son of Achilles, but Achilles Himself': Alcibiades' Entry on the Political Stage at Athens II", Historia: Zeitschrift für Alte Geschichte 39.1, 1-19.

» Borg, B. E. (ed.) (2004). Paideia: The World of the Second Sophistic. Berlin: Walter de Gruyter.

" Bowersock, G. W. (1969). Greek sophists in the Roman Empire. Oxford: Clarendon Press.

» Bowie, A. M. (1996). Aristophanes: Myth, Ritual and Comedy. Cambridge: University Press.

" Bowie, E. L. (1970). "The Greeks and Their Past in the Second Sophistic". Past and Present 46.1, 3-41.

» Braund, D. C. (1993). "Dionysiac tragedy in Plutarch, Crassus". CQ 43, 468-474

» Bréchet, C. (1999). "'Le 'De audiendis poetis' de Plutarque et le procès platonicien de la poésie", RPh 73.2, 209-244.

» Burns, T. W. (2012). "Nicias in Thucydides and Aristophanes Part I: Nicias and Divine Justice in Thucydides". Polis 29.2, 217-233.

»Candau, J. M. (2011), "Plutarco y la Historiografía Trágica”. En: Candau, J.M. et al. (eds.). Plutarco transmisor. Actas del X simposio internacional de la Sociedad española de Plutarquistas. Sevilla: Universidad de Sevilla, 147-169.

» Carrière, J.C. (1983). Le carnaval et la politique: une introduction à la comédie grecque suivie d'un choix de fragments. Besançon: Université de Franche-Comté.

" Castelnérac, B. (2008). "Plutarch's Life of Lycurgus and the Philosophical Use of Discourse". En: Nikolaidis, A. (ed.). The Unity of Plutarch's Work: 'Moralia' Themes in the 'Lives', Features of the 'Lives' in the 'Moralia'. Berlin: Walter de Gruyter, 427-444. 
" Christodoulou, P. (2013). "Thucydides' Pericles. Between Historical Reality and Literary Representation". En: Tsakmakis, A.; Tamiolaki, M. (eds.). Thucydides Between History and Literature. Berlin-Boston: Walter de Gruyter, 225-254.

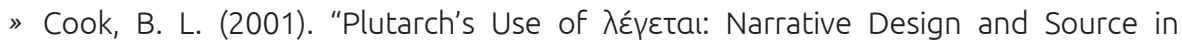
Alexander", GRBS 42, 329-360.

» Crick, N. (2015). Rhetoric and Power: The Drama of Classical Greece. South Carolina: University of South Carolina Press.

» Csapo E. (2002). "Kallipides on the Floor-Sweepings: The Limits of Realism in Classical Acting and Performance Styles.". En: Easterling, P.; Hall, E. (eds.). Greek and Roman Actors: Aspects of an Ancient Profession. Cambridge: University Press, 126-147.

" Csapo, E. (2004). "Social and Economic Conditions Behind the Rise of the Acting Profession in the Fifth and Fourth Centuries BC". En: Hugoniot, C.; Hurlet, F.; Milanezi, S. (eds.). Le statut de l'acteur dans l'Antiquité grecque et romaine. Tours: Presses universitaires François-Rabelais. http://books.openedition.org/pufr/8560.

" Csapo, E.; Slater, W. (1995). The Context of Ancient Drama. Michigan: University of Michigan Press.

"Dalby, A. (1991). "The Curriculum Vitae of Duris of Samos", CQ 41.2, 539-541.

"De Lacy, P. (1952). "Biography and Tragedy in Plutarch", AJPh 73.2, 159-171

"Desideri, P. (2012). Saggi su Plutarco e la sua fortuna. Firenze: University Press.

" Di Gregorio, L. (1976). "Plutarco e la tragedia greca”, Prometheus 2, 151-174.

" Duff, T. (1999). Plutarch's Lives: Exploring Virtue and Vice. Oxford: University Press.

"Duff, T. (2005). "The First Five Anecdotes of Plutarch's Life of Alkibiades". En Blois, L. et al. (eds.). The Statesman in Plutarch's Works, Vol. II. Proceedings of the Sixth International Conference of the International Plutarch Society, Nijmegen/Castle Hernen, May 1-5, 2002, Leiden. Boston: Brill, 157-166.

» Engels, J. (1998). "1002 (=107) Stesimbrotos of Thasos". En: Bollansée, J.; Engels, J.; Schepens, G.; Theys, E. (eds.). Felix Jacoby Die Fragmente der griechischen Historiker Continued Part IV Biography and Antiquarian Literature, IV A: Biography, fasc. 1: The Pre-Hellenistic Period. Leiden-Boston-Köln: Brill, 50-59.

» Flacelière, R. (1963). "Rome et ses empereurs vus par Plutarque", L'antiquité classique 32.1, 28-47.

» Flacelière, R. ; Chambry, E. (eds.) (2003). Plutarque, Vies (XVI tomes), avec le concours de M. Juneaux pour les t. I et II, 2e tirage. Paris: Les Belles Lettres.

"Fornara, C. W.; Samons, L. J. (1991). Athens from Cleisthenes to Pericles. Berkeley: University of California Press.

"Fornis, C. (2012). "Laconismo frente a retórica. Aforismo y brevilocuencia en el lenguaje espartano". En: Sancho Rocher, L. et al. (eds.). Lógos y arkhé. Discurso político y autoridad en la Grecia antigua. Buenos Aires: Miño y Dávila, 49-67.

" García Soler, M. J. (2013). "La crítica de los políticos en la Comedia Antigua", Humanitas $65,55-70$.

"Gallego, J. (2003). La democracia en tiempos de tragedia: Asamblea ateniense y subjetividad política. Buenos Aires-Madrid: Miño y Dávila.

» Gil Fernández, L. (1962). "La semblanza de Nicias en Plutarco", EClás 6, 404-450.

" Goldhill, S. (2001). Being Greek Under Rome: Cultural Identity, the Second Sophistic and the Development of Empire. Cambridge: University Press. 
" Gomme, A. (1938). "Aristophanes and Politics". CR 52.3, 97-109.

» Grant, M. (1970). The Ancient Historians. New York: Charles Scribner's Sons.

»Gribble, D. (1999). Alcibiades and Athens. A Study in Literary Presentation. Oxford: University Press.

» Hall, E. (2006). The Theatrical Cast of Athens: Interactions between Ancient Greek Drama and Society. Oxford: University Press

» Hall, E. (2007). "Greek Tragedy 430-380 BC". En: Osborne, R. (ed.). Debating the Athenian Cultural Revolution: Art, Literature, Philosophy, and Politics 430-380 BC. Cambridge: University Press, 264-287.

" Harding, P. (1994). "Comedy and Rhetoric". En: Worthington, I. (ed.). Persuasion: Greek Rhetoric in Action. London-New York: Routledge, 196-221.

"Hobbs, A. (2006). Plato and the Hero: Courage, Manliness and the Impersonal Good. Cambridge: University Press.

» Holden, H. (1887). Plutarch's Life of Nikias. With introduction, notes, and lexicon. Cambridge: University Press.

" Huxley, G. (1965). "Ion of Chios", GRBS 6.1, 29-46.

»Jacoby, F. (1947). "Some Remarks on Ion of Chios", CQ 41.1/2, 1-17.

» Jones, C. (1971). Plutarch and Rome. Oxford: Clarendon Press.

» Lateiner, D. (1985). "Nicias' Inadequate Encouragement (Thucydides 7.69.2)", CPh $80.3,201-213$.

" Lawler, L. (1944). "The Dance of the Ancient Mariners", TAPhA 75, 20-33.

»Lenfant, D. (2003). “De l'usage des comiques comme source historique: les Vies de Plutarque et la Comédie Ancienne". En: Lachenaud, G.; Longree, D. (eds.). Grecs et Romains aux prises avec l'histoire. Rennes: Presses universitaires, 391-414.

» Liebert, H. (2009). "Plutarch's critique of Plato's best regime", History of Political Thought 30.2, 251-271.

» LSJ = Liddell, H. G.; Scott, R.; Jones, H. S. (1996). A Greek-English Lexicon. Oxford: Clarendon Press.

» Meister, K. (1978). "Stesimbrotos' Schrift über die athenischen Staatsmänner und ihre historische Bedeutung (FGrHist 107 F 1-11)", Historia: Zeitschrift Für Alte Geschichte 27.2, 274-294.

» Michelakis, P. (2007). Achilles in Greek Tragedy. Cambridge: University Press.

" Milanezi, S. (2004). "À l'ombre des acteurs: les amuseurs à l'époque classique". En: Hugoniot, C.; Hurlet, F.; Milanezi, S. (eds.). Le statut de l'acteur dans l'Antiquité grecque et romaine. Tours: Presses universitaires François-Rabelais. http://books.openedition. org/pufr/8560.

" Mossman, J. M. (1988). "Tragedy and epic in Plutarch's Alexander", JHS 108, 83-93.

» Mueller H. F. (1995). "Images of Excellence: Visual Rhetoric and Political Behavior". En: Gallo I.; Scardigli, B. (eds.). Teoría e Prassi Politica nelle Opere di Plutarco. Atti del $\checkmark$ Convegno Plutarcheo (= IIIrd International Conference of the International Plutarch Society), Certosa di Pontignano, 7-9 giugno 1993). Napoli: D'Auria, 287-300.

» Muñoz Gallarte, I. (2013). "The tragic actor in Plutarch". En: Casanova, A. (ed.). Figure d'Atene nelle opere di Plutarco. Firenze: University Press, 69-81.

» Naas, V.; Simon, M. (eds.). (2016). De Samos à Rome: personnalité et influence de 
Douris. Paris: Presses Universitaires de Paris Ouest.

" O'Connell, P. A. (2017). "Enargeia, persuasion, and the vividness effect in Athenian forensic oratory". Advances in the History of Rhetoric 20.3, 225-251.

" O'Donnell, E. A. (1975). The Transferred Use of Theater Terms as a Feature of Plutarch's Style. Dissertation. University of Pennsylvania.

"Ober, J. (1991). "Public speakers and mass audiences". En: Ober, J. Mass and Elite in Democratic Athens. Rhetoric, Ideology, and the Power of the People. Princeton: University Press, 104-156.

"Olinski, T. M. (2016). The Apophthegmata Lakonika and Greek Perceptions: Identifying Authentic Spartan Traits from the Spartan mirage. Doctoral dissertation, Queen's University (Canada).

"Ollier, F. (1933). Le mirage spartiate. Étude sur l'ide冈alisation de Sparte dans l'antiquite冈 grecque de l'origine jusqu'aux cyniques. Paris: E. de Boccard.

» Olson, D. (2010). "Comedy, Politics, and Society". En: Dobrov, G. W. (ed.). Brill's Companion to the Study of Greek Comedy. Leiden-Boston: Brill.

"Pace, A. (2017). "Mimesi attoriale e vita politica nelle immagini letterarie di Plutarco". En: Amendola, S. et al. (eds.). Immagini letterarie e iconografia nelle opere di Plutarco. Madrid: Ediciones Clásicas.

»Papadi, D. (2005). "Theatricality and dramatic vocabulary in Plutarch's Moralia. How to tell a flatterer from a friend". En: Jufresa, M. et al. (eds.). Plutarc a la seva època: Paideia i societat. Actas del 8. Simposio español sobre Plutarco, Barcelona, 6-8 de noviembre de 2003. Barcelona: Sociedad Española de Plutarquistas, 401-411.

" Papadi, D. (2007). Tragedy and Theatricality in Plutarch. PhD thesis. London: University of London.

» Pauw, D. (1980). "Impersonal Expressions and Unidentified Spokesmen in Greek and Roman Historiography and Biography", AClass 23, 83-95.

" Pébarthe, C. (2010). "La vie politique des athéniens illustres au Ve siècle. Périclès, Thucydide et Plutarque". En: Capdetrey, L. ; Lafond, Y. (eds.). La cité et ses élites. Pratiques et représentation des formes de domination et de contrôle social dans les cités grecques. Actes du colloque de Poitiers, 19-20 octobre 2006. Paris: De Boccard, 273-290.

»Pelling, C. (1988). Plutarch. Life of Antony. Cambridge: CGLC.

»Pelling, C. (2002). "Plutarch and Thucydides": En: Stadter, P. (ed.). Plutarch and History. London: Routldge, 10-40.

"Pelling, C. (2007). "Ion's Epidemiai and Plutarch's Ion". En: Jennings, J.; Katsaros, A. (eds.). The World of Ion of Chios, Leiden: Brill, 75-109.

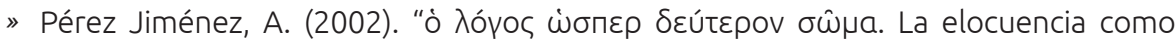
instrumento político en las Vidas paralelas de Plutarco", CFC(C) 12, 253-270.

»Perrin, B. (1902). "The Nikias of Pasiphon and Plutarch", TAPhA 33, 139-149.

» Philippon, A., J. Sirinelli et al. (1972-2004). Plutarque: Euvres Morales. Paris: Les Belles Lettres.

»Plett, H. (2012). Enargeia in Classical Antiquity and the Early Modern Age: The Aesthetics of Evidence. Leiden: Brill.

"Plümacher, E. (2004). Geschichte und Geschichten: Aufsätze zur Apostelgeschichte und zu den Johannesakten. Tübingen: Mohr Siebeck. 
" Rawson, E. (1969). The Spartan Tradition in Western Thought. Oxford: University Press.

» Reichardt, C. (2008). Sprachlich-stilistische Untersuchungen zu den frühen römischen Historikern. Bamberg: University of Bamberg Press.

" Revermann, M. (1999). "Euripides, Tragedy and Macedon: Some Conditions of Reception", ICS 24/25, 451-467.

» Revermann, M. (2011). Comic business. Theatricality, dramatic technique, and performance contexts of Aristophanic comedy. Oxford: University Press.

» Rocha, R. (2014). "A Esparta de Plutarco entre a guerra e as artes". En: Gómez Cardó, P.; Leão, D.; Oliveira Silva, M. (eds.), Plutarco entre mundos: visões de Esparta, Atenas e Roma. Coimbra: University Press.

" Rood, T. (2002), "Nikias and Athens". En: Rood, T. Thucydides: Narrative and Explanation: Narrative and Explanation. Oxford: University Pres, 183-204

"Rosenbloom, D. (2009). "Staging rhetoric in Athens". En: Gunderson, E. (ed.). The Cambridge Companion to Ancient Rhetoric. Cambridge: University Press, 194-211.

"Saïd, A. (2005). "Plutarch and the People in the Parallel Lives". En: De Blois, L. et al. (eds.). The Statesman in Plutarch's Works. Vol. II. Proceedings of the Sixth International Conference of the International Plutarch Society, Nijmegen / Castle Hernen, May 1-5, 2002. Leiden-Boston: Brill, 7-25.

» Salcedo Parrondo, M. (2005). "Retórica visual y carácter politico, Alc.10: un modelo negativo de enargeia". En De Blois, L. et al. (eds.). The Statesman in Plutarch's Works, Vol. II. Proceedings of the Sixth International Conference of the International Plutarch Society, Nijmegen / Castle Hernen, May 1-5, 2002. Leiden-Boston: Brill, 179-186.

"Sansone, D. (2012). Greek Drama and the Invention of Rhetoric. Sussex: John Wiley \& Sons.

» Sapere, A. (2014). "Descripción externa e introspección subjetiva en la Vida de Nicias de Plutarco", Flll 25, 139-155.

"Schachermeyr, F. (1965). "Stesimbrotos und seine Schrift über die Staatsmänner", SAVVW247, 1-25.

» Schmitz, T. (1997). Bildung und Macht, Zur sozialen und politischen Funktion der zweiten Sophistik in der griechischen Welt der Kaiserzeit. München: Beck.

" Schoeck, R J. (1956). "More, Plutarch, and King Agis: Spartan History and the Meaning of Utopia", PhQ 35, 366-375.

» Shipley, D. R. (1997). A Commentary on Plutarch's Life of Agesilaos: Response to Sources in the Presentation of Character. Oxford: University Press.

» Silva, M. A. de Oliveira (2005). "Escrita e poder em Plutarco", Dimensôes 17, 91-103.

"Silva, M. A. de Oliveira (2006). "Plutarco e a Segunda Sofística”, Clássica 19.2, 257-264.

"Silva, M. A. de Oliveira (2007). Plutarco e Roma: O Mundo Grego no Império. São Paulo: FFLCH-USP.

» Silva, M. A. de Oliveira (2011). "Política e Retórica na Grécia Antiga: uma leitura da biografia plutarquiana de Alcibíades", Historiæ 2.1, 153-164.

» Slater, W. (2007). 'Deconstructing Festivals'. En: Wilson, P. (ed.). The Greek Theatre and Festivals: Documentary Studies. Oxford: University Press, 21-47.

» Soares, M. T. M. (2011). "Ekphrasis e enargeia na historiografia de Tucídides e no pensamento filosófico de Paul Ricoeur", Talia dixit 6, 1-23. 
"Stadter, P. (1987). "The Rhetoric of Plutarch's Pericles", AncSoc 18, 251-269.

»Stadter, P. (1989). A Commentary on Plutarch's Pericles. ChapelHill: University of North Carolina Press.

" Stadter, P. \& L. Van der Stockt (eds.) (2002). Sage and emperor: Plutarch, Greek intellectuals, and Roman power in the time of Trajan (98-117 A. D.). Leuven: University Press.

"Stanford, W. B. (2014). Greek Tragedy and the Emotions: An Introductory Study. London: Routledge ( $1^{\circ}$ ed. 1993).

"Strasburger, H. (1986). "Aus den Anfängen der griechischen Memoirenkunst. Ion von Chios und Stesimbrotos von Thasos". En: Schlink, W.; Sperlich, M., Forma et subtilitas. Festschrift für Wolfgang Schöne zum 75. Geburtstag. Berlin: Walter de Gruyter, 1-11.

"Swain, S. (1996). Hellenism and Empire: Language, Classicism, and Power in the Greek World, $A D$ 50-250. Oxford: University Press.

"Tagliasacchi, A. (1960). "Plutarco e la tragedia greca", Dioniso 34, 124-142.

» Taplin, O. (1993). Comic Angels and Other Approaches to Greek Drama through VasePaintings. Oxford: Clarendon Press.

"Taplin, O. (1999). "Spreading the word through performance". En: Goldhill, S.; Osborne, R. (eds.). Performance Culture and Athenian Democracy. Cambridge: University Press.

" Tigerstedt, E. (1974). The Legend of Sparta in Classical Antiquity. StockholmGöteborg-Uppsala: Almqvist \& Wiksell.

» Titchener, F. B. (2008). "Is Plutarch's Nicias Devout, Superstitious, or Both?". En: Nikolaidis, A. (ed.). The Unity of Plutarch's Work: 'Moralia' Themes in the 'Lives', Features of the 'Lives' in the 'Moralia'. Berlin: Walter de Gruyter, 277-283.

"Tsakmakis, A. (1995). "Das historische Werk des Stesimbrotos von Thasos", Historia: Zeitschrift Für Alte Geschichte 44.2, 129-152.

» Valgiglio, E. (1967). "Il tema della poesia nel pensiero di Plutarco", Maia 19, 319-355.

»Van der Stockt, L. (1990). "L'expérience esthétique de la mimèsis selon Plutarque", QUCC 36, 23-31.

"Vanotti, G. (2010). "A proposito di Stesimbroto di Taso in Suda [A 2681 Adler]", Themata 6, 135-162.

"Vanotti, G. "Plutarco 'lettore' di Stesimbroto di Taso (nota a FGrHist 107/1002 F5 = Plutarco, Cimone xiv)", Themata 9, 61-87.

"Vanotti, G. (2011). "Il giudizio di Plutarco su Stesimbroto di Taso in FF 10b e 11". En: Pace, G.; Volpe Cacciatore, P. (eds.). Plutarch's Writings: Transmission, Translation, Reception, Commentary. Proceedings of the IX International Conference of the International Plutarch Society Ravello - Auditorium Oscar NiemeyerSeptember 29 October 1, 2011. Napoli: D'Auria, 447-454.

» Verdegem, S. (2010). Plutarch's Life of Alcibiades: Story, Text and Moralism. Leuven: University Press.

» Von Wilamowitz-Möllendorff, U. (1877). "Die Thukydideslegende", Hermes 12.3, 326367.

»Walbank, F. W. (1960). "History and Tragedy", Historia 9.2, 216-234.

»Walker, A. (1993). "Enargeia and the Spectator in Greek Historiography". TAPhA 123, 353-377. 
"Webb, R. (2016). Ekphrasis, imagination and persuasion in ancient rhetorical theory and practice. London: Routledge.

»Westlake, H. D. (1941). "Nicias in Thucydides", CQ 35.12, 58-65.

»Whitby, M. (2002). Sparta, New York, London: Routledge / Classical Press of Wales.

"Whitmarsh, T. (2005), The Second Sophistic. Cambridge: University Press.

"Wilson, P. (2000). The Athenian Institution of the Khoregia. The chorus, the city and the stage. Cambridge: University Press.

"Wilson, P. (2008). "Costing the Dionysia". En: Revermann, M.; Wilson, P. (eds.). Performance, Iconography. Reception Studies in Honour of Oliver Taplin. Oxford: University Press, 88-127.

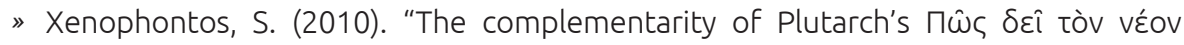

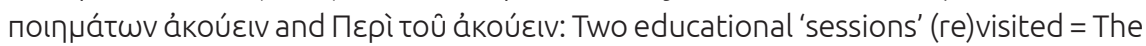
Complementarity of Plutarch's Quomodo adolescens poetas audire debeat and De recta ratione audiendi: Two educational 'sessions' (re)visited", Rosetta 8.5, 164-185.

»Xenophontos, S. (2016). Ethical Education in Plutarch: Moralising Agents and Contexts. Berlin-Boston: Walter de Gruyter.

»Xifra, J. (2019). "Comedia Antigua, intelectuales públicos y los orígenes de la comunicación de disenso: el caso de Aristófanes", Gerión 37.1, 9-33. https://doi. org/10.5209/GERI.63866

"Zadorojniy, A. (1997). "Tragedy and epic in Plutarch's Crassus", Hermes 125, 169-182.

"Zadarojniy, A. (2002). "Safe Drugs for the Good Boys: Platonism and Pedagogy in Plutarch's De audiendis poetis?", En: Stadter, P.; Van der Stockt, L. (eds.). Sage and emperor. Leuven: University Press, 297-330.

"Zangara, A. (2008). "Voir l'histoire. Théories anciennes du récit historique: Présentation", Anabases 7, 249-256. 